\title{
Greenhouse Gas Emissions and Eco-Performance at Farm Level: A Parametric Approach
}

\author{
Christian Stetter $^{1}$ (D) . Johannes Sauer ${ }^{1}$
}

Accepted: 7 December 2021 / Published online: 19 January 2022

(c) The Author(s) 2022

\begin{abstract}
Agriculture is an important source of greenhouse gas (GHG) emissions and thus contributes considerably to global warming. However, farms can vary substantially in terms of their climatic impact. So far, most policies aiming at reducing GHG emissions from farming have largely been based on findings at the aggregate level, without taking farm heterogeneity properly into account. This study seeks to provide a better understanding of the GHG mitigation potential at the micro-level. We develop a comprehensible analytical framework for analyzing economic-ecological performance by way of stochastic frontier analysis. We introduce the concept of emission efficiency, where we distinguish between persistent and time-varying efficiency. We further analyze farms with respect to their emission-performance dynamics. Results from our (2005-2014) empirical application from Bavaria - an important region for the EU - show considerable differences in farm-level GHG emissions across different farm types. The same applies to emission efficiencies. Overall, emission performance improved over time. The results have important climatepolicy implications as they help to provide better target measures for mitigating GHG emissions from agriculture, without compromising economic performance levels.
\end{abstract}

Keywords Agricultural greenhouse gas emissions - Climate change mitigation · Ecoperformance decomposition · Economic-ecological efficiency $\cdot$ Stochastic frontier analysis

\section{Introduction}

Climate change - and its predicted consequences - has been a major topic of interest in research, in politics and the public sphere for several decades. The discussion also highly affects agriculture as it is a driving force behind global warming, accounting for approximately $14 \%$ greenhouse gas (GHG) emissions worldwide (European Environment Agency 2019). According to the Food and Agriculture Organization of the United Nations (FAO

Christian Stetter

christian.stetter@tum.de

Johannes Sauer

jo.sauer@tum.de

1 Agricultural Production and Resource Economics, Technical University of Munich, Alte Akademie 14, 85354 Freising, Germany 
2017), climate change is among the biggest challenges agriculture is currently facing in terms of both mitigation and adaptation. The European Union (EU) has acknowledged the impact of farming on climate change and vice versa. Therefore, the European Commission (2019a) has declared climate change mitigation as a specific objective of the future Common Agricultural Policy (CAP). While farmers in the EU are expected to reduce their GHG emissions, the global need for food, fiber and bioenergy from agriculture is steadily rising (FAO 2017), i.e. agricultural productivity must further increase. This raises the question as to what extent farmers can boost their production while at the same time limiting their release of greenhouse gas emissions into the atmosphere.

In this study, we analyze the performance of farms, giving equal weighting to economic success and to the emission of greenhouse gases. More specifically, our research objective is two-fold. First, we develop a parametric eco-efficiency concept capable of jointly evaluating the ecological and economic performance of businesses over time. Usually, ecoefficiency is analyzed in a nonparametric data envelopment setting. The idea behind the parametrization is to overcome some of the conceptual limitations faced by the model in a nonparametric setting. Second, we seek to approximate GHG emissions for a large sample of German farms by using a novel approach based on the guidelines for national GHG inventories of the Intergovernmental Panel on Climate Change (IPCC 2006).

Over recent decades, the concept of ecological-economic efficiency, or "eco-efficiency" has gained recognition as a way of evaluating the balance between economic performance and the environmental damage induced by economic activity. Starting with the article by Kuosmanen and Kortelainen (2005), who operationalized the eco-efficiency concept to be calculated by means of data envelopment analysis (DEA), numerous studies in several fields followed, both at the micro- and at the macro-level. Literature focusing on the trade-off between greenhouse gas emissions and economic performance is sparse. Camarero et al. (2014) and Gómez-Calvet et al. (2016) analyze this relationship for European countries. Multiple authors have utilized the above-mentioned eco-efficiency concept in the farming context, ranging from livestock and arable farming to olive growing and horticulture (Picazo-Tadeo, Gómez-Limón, and Reig-Martínez 2011; Picazo-Tadeo, BeltránEsteve, and Gómez-Limón 2012; Gadanakis et al. 2015; Pérez Urdiales, Lansink, and Wall 2016; Bonfiglio, Arzeni, and Bodini 2017; Godoy-Durán et al. 2017). Several methodological advancements have been suggested in the literature. For instance, Picazo-Tadeo, Beltrán-Esteve, and Gómez-Limón (2012) use a directional distance function to asses the ecoefficiency of Spanish olive-growers. Beltrán-Esteve et al. (2014) extend this approach and make use of the metafrontier approach proposed by O'Donnell, Rao, and Battese (2008). Furthermore, Kortelainen (2008) embedded the concept of eco-efficiency into a dynamic setting allowing for comparisons over time. In an attempt to transfer the eco-efficiency concept to a parametric setting, Orea and Wall (2017) study the eco-efficiency of Spanish dairy farms in a stochastic frontier setting. Many of the aforementioned studies-and micro-level studies particularly-are rather limited in terms of their scope. For instance, none of the mentioned micro-studies on agriculture have implemented a dynamic approach yet. Also, although having acknowledged the possibility of variable returns to the scale of environmental pressures, very few studies account for it (Bonfiglio, Arzeni, and Bodini 2017). What is more, none of the studies have implemented the possibility of a non-linear structure when building composite indicators of environmental pressures. According to Beltrán-Esteve et al. (2014), one reason for the limited scope of many works on ecoefficiency is the lack of appropriate environmental data at the micro-level. This is also true for GHG emissions. Farms can vary substantially regarding their climatic impact. So far, most policies aiming at reducing GHG emissions from farming have largely been based on 
findings at the aggregate level, without taking farm heterogeneity properly into account. Recent attempts have been made to obtain GHG data at farm level. Coderoni and Esposti (2014) and Baldoni, Coderoni, and Esposti (2017) present a methodology to gather GHG emissions primarily based on farm accountancy data. Further applications of this method can be found in Baldoni, Coderoni, and Esposti (2018) and Coderoni and Esposti (2018).

This study contributes to the literature by first conceptually extending the eco-efficiency approach based on Kuosmanen and Kortelainen (2005) and Orea and Wall (2017) to a more general stochastic frontier setting. By parameterizing the concept, we allow for variable returns to environmental pressure scale, a nonlinear structure of composite ecological damage, and for inter-temporal comparisons. Furthermore, we decompose eco-performance dynamics into ecological-technical change, eco-efficiency change and scale change, based on a generalized Malmquist productivity index (Orea 2002). We are able to show that our theoretical approach is equally valid for micro- and the macro-level analyses. In our empirical case study, we construct a unique panel dataset and demonstrate how to appropriately approximate GHG emissions at the micro-level, based on multiple data sources for farms in the German federal state of Bavaria. Finally, by applying a state-of-the-art stochastic frontier model, we are able to further distinguish between permanent and time-varying ecoefficiency (Kumbhakar, Lien, and Hardaker 2014). We show how to assess farms' emission performance, i.e. their capability to produce goods and services while causing minimal climatic stress. By relating eco-performance to greenhouse gas emissions, it is possible to detect the relative GHG mitigation potential of individual farms. Such robust evidence is essential for managers and policy-makers that aiming at further optimizing their economicecological performance by reducing the release of atmospheric GHGs.

The remainder of this article is organized as follows. In Sect. 2, we develop the conceptual framework for the empirical analysis. In Sect. 3 we outline the data-construction process and provide relevant summary statistics. In Sect. 4, we present our empirical model and estimation strategy. Section 5 gives a description and discussion of the empirical findings, along with the policy implications thereof. The final Sect. 6 summarizes and concludes the limitations of the study, and potential directions for further research.

\section{Conceptual Framework}

\subsection{A Parametric Stochastic Frontier Approach to Eco-Efficiency}

In order to analyze the economic-ecological performance of businesses, we build upon and further develop the frontier setting developed by Kuosmanen and Kortelainen (2005) and Orea and Wall (2017). We base our approach on the definition of eco-efficiency from the literature on ecological economics. Eco-efficiency is defined as the ratio between economic performance $y$ (traditionally value added) and environmental damage $(D)$. Suppose we observe a set of $k=1, \ldots K$ comparable production units which generate economic output $y$ each year in period $t=1, \ldots T$ through $n=1, \ldots N$ environmental pressures $\mathbf{s}^{\mathbf{t}}=\left(s_{1}^{t}, \ldots, s_{N}^{T}\right)$ that damage the ecological system.

There are numerous ways to generate economic output which vary in their environmental impact (Kuosmanen and Kortelainen 2005). Therefore, we introduce the time-dependent pressure-generating technology set (Kuosmanen and Kortelainen 2005; Kortelainen 2008; Picazo-Tadeo, Beltrán-Esteve, and Gómez-Limón 2012): 


$$
\text { PGTS }_{t}=\left[\left(y_{t}, \mathbf{s}_{t}\right) \in \mathbb{R}_{+}^{N+1} \mid \text { economic output } y_{t} \text { can be generated with ecological pressures } \mathbf{s}_{t}\right]
$$

It contains all technically and economically feasible combinations of economic outcome (y) and environmental pressures (s) in period t. It is further assumed that all production units have a common underlying pressure-generating technology.

Note that this concept relates to economic and environmental pressures in a non-physical sense. Greenhouse gas emissions (and other environmental pressures) are therefore looked at from an impact-based point of view as opposed to a quantity-based point of view. As Kuosmanen and Kortelainen (2005) state, this is a fundamental presupposition for the eco-efficiency concept. Physical inputs and outputs that affect economic outcome and those that have an impact on the environment are implicitly included in $y$ and $\mathbf{s}$. This is different from more traditional environmental economics approaches that use inputs and outputs as key elements of their models. ${ }^{1}$

\subsubsection{Eco-Performance}

Most studies (e.g. Kuosmanen and Kortelainen 2005; Pérez Urdiales, Lansink, and Wall 2016) base their analyses on the eco-efficiency concept, which is defined as the ratio of economic value added and environmental pressures. Leaning on this approach, we define eco-performance (EP) at time $\mathrm{t}$ as follows:

$$
E P^{t}=\frac{\text { Economic output }^{t}}{\text { Environmental pressure }^{t}}=\frac{y^{t}}{D\left(s_{1}^{t}, s_{2}^{t}, \ldots, s_{N}^{t}\right)}
$$

where $D\left(s_{1}^{t}, s_{2}^{t}, \ldots, s_{N}^{t}\right)$ is a function that reflects the environmental damage associated with the individual ecological pressures/environmental stress factors $\mathbf{s}$ at time $\mathbf{t}$.

As can be seen from (2), we depart from the traditional definition of eco-efficiency in several ways. In line with Kortelainen (2008) and Picazo-Tadeo, Castillo-Giménez, and Beltrán-Esteve (2014), we define the above-mentioned ratio as eco-performance. Equation 2 does not deliver any benchmark or baseline for which to compare given levels of performance as assumed by the relative concept of eco-efficiency. Therefore to clearly distinguish between the absolute concept presented in (2) and eco-efficiency, we choose the term eco-performance (Kortelainen 2008). ${ }^{2}$ What is more, we define eco-performance in a more

\footnotetext{
1 In that sense, the presented concept deviates from multiple analyses on production in the presence of undesirable outputs or by-products, respectively (Førsund 2018; Malikov, Bokusheva, and Kumbhakar 2018; Atkinson and Tsionas 2018). In these studies, pollutants such as nitrogen surpluses or $\mathrm{CO}_{2}$ emissions are considered physical quantities. Put differently, the approach presented in this study rather relates to the field of ecological economics as opposed to environmental economics, where emission quantities are assumed. Here, we seek to relate ecological pressures to economic outcome, which is distinctly different from the above-mentioned approaches that seek to model the relationship between physical inputs and outputs of a production process. In our approach, we do not explicitly model the input-output relationship. Note however, through relating ecological pressures to economic outcome the underlying production technology is implicitly contained in the model, although not explicitly modeled. For instance, GHG emissions are a result of the use of inputs such as fertilizers or livestock. Hence, these inputs are reflected by GHG emissions in our PGTS.

2 Throughout this study, we use the terms eco-performance, environmental performance as suggested by Kortelainen (2008) and eco-productivity interchangeably. We defer from using the term 'environmental productivity' to avoid confusion, as this term has previously been used in different contexts (e.g. Ball et al. 2004; Managi et al. 2005; Managi 2006).
} 
general sense, in that we do not restrict the economic outcome variable to be value added. We select farm revenues $(r)$ as the economic outcome variable of choice. This is mainly because we argue that revenues are economically more relevant to farmers than economic value added. Given binding regulatory and expenditure constraints with respect to inputs, Chambers and Lee (1986), and Kumbhakar and Bokusheva (2009) show that most farms aim at maximizing revenues (or equivalently outputs).

As highlighted by Kortelainen (2008), the absolute value of eco-performance is not very informative and hardly interpretable as such. Therefore, we will focus on the assessment of change rates in eco-performance by making use of an eco-performance index. We will return to this issue in Sect. 2.2.

\subsubsection{The Stochastic Frontier Pressure Conversion Model}

Representing the pressure-generating technology (1) by a functional form, we obtain a function that provides the relationship between environmental stress $\mathbf{s}$ and economic outcome $y$, where, for now, no inefficiency is assumed: ${ }^{3}$

$$
y=D\left(s_{1}, s_{2}, \ldots, s_{N} ; \boldsymbol{\beta}\right)
$$

aside from the known elements in the equation, $\boldsymbol{\beta}$ represents a parameter vector to be estimated. We call (3) a pressure conversion function as it describes how ecological pressures (independent variables) are converted to economic outcome (dependent variable). Hence, economic outcome is expressed as a function of ecological damage caused by environmental pressures. As Orea and Wall (2017) note, the parametric specification of Eq. 3 allows us to evaluate the marginal contribution of pressure $s_{n}$ to the economic outcome $y$ of production unit $k$ at time $t$. For instance, it is possible to assess by how much the economic output decreases if the $n$-th pressure is decreased by one unit (percent), ceteris paribus. Thus, we can also assess which environmental pressure may be most costly to reduce for a given firm $k$. A major concern could be that the omission of capital and labor in our framework might lead to omitted variable bias (OVB) since capital and labor are commonly modeled as key inputs to production technologies. If labor and capital are fixed over the analyzed time period, the specified fixed-effects model can reliably remove these variables. In farming, labor and capital are often by definition fixed in the long-term. This assumption appears to be rather sensible in the Bavarian farming context. What is more, OVB occurs only when the omitted variables are both correlated with the independent variables as well as with the dependent model. We do not expect this to be a major problem in our application. We included a robustness check in the Appendix A.6, where we estimated alternative specifications of the pressure conversion function that included capital and labor as independent variables. As expected, we could not find indication for the presence of omitted variable bias due to these two variables.

Equation 3 neglects the fact that not all farms generate the economically feasible maximum level of revenue, given their level of environmental damage. To account for (ecological) inefficiency and statistical noise, (3) can be expressed as a stochastic frontier following Aigner, Lovell, and Schmidt (1977) and Meeusen and van den Broeck (1977):

\footnotetext{
3 To avoid notational clutter, we omit the subscripts for time $t=1, \ldots T$ and the production units $k=1, \ldots K$.
} 


$$
y=D\left(s_{1}, s_{2}, \ldots, s_{N} ; \boldsymbol{\beta}\right) e^{-u+v}
$$

where $\epsilon=-u+v$ represents a composite error term consisting of an ecological inefficiency component $(u)$ and statistical noise $(v)$. We assume that environmental damage is monotone in the sense that it cannot decrease, ceteris paribus, if any environmental pressure is increased. Since $y=D(s)$, monotonicity must also hold for Expression 3, which is a necessary condition for obtaining a sensible interpretation of individual (eco-)efficiency scores (Sauer, Frohberg, and Hockmann 2006; Henningsen and Henning 2009). One major advantage of choosing a parametric approach over DEA is the fact that we can account for stochastic noise and thus take into account the effect of random shocks, outliers and measurement errors. Contrary to previous DEA-based studies on eco-efficiency, our parametric approach allows us to specify $D(s)$ in a nonlinear fashion. This relates to the relationship between environmental pressures and ultimate environmental damage. Kortelainen (2008, p. 703) states "[...] the relationship between the environmental pressure and the ultimate environmental impact can be complex, nonlinear, and very difficult to predict". In that sense, the presented framework might better grasp underlying nonlinearities.

\subsubsection{Returns to Pressure Scale}

There are two major perspectives concerning the question if the pressure-generating technology exhibits exhibits constant or variable returns to scale (Picazo-Tadeo, BeltránEsteve, and Gómez-Limón 2012). From an ecological point of view, farming could be considered a constant returns to scale (CRS) activity as the effect of farming on the environment is directly related to agricultural practices rather than to the allocation of land and other inputs into individual farms (Picazo-Tadeo, Gómez-Limón, and Reig-Martínez 2011; Picazo-Tadeo, Beltrán-Esteve, and Gómez-Limón 2012). However, from an economic point of view, returns to pressure scale of farming activities could also be considered variable because ecological pressures often depend on the use of inputs both in terms of quantity as well as intensity. As the input-output relationship in farming is usually described by variable returns to scale (VRS), this is also likely for returns to pressure scale (Bonfiglio, Arzeni, and Bodini 2017). As the imposition of CRS would a priori imply linearity between emissions and economic outcome, we decide to relax the more restrictive assumption of constant returns to pressure scale. In allowing returns to pressure scale to be variable, we can actually empirically test which of the two perspectives on pressure scale is more realistic.

\subsubsection{Eco-Efficiency}

In the spirit of Shepard's technical efficiencies, we define eco-efficiency as the ratio between the observed economic output and the frontier economic output:

$$
E E=\frac{y}{D\left(\boldsymbol{s}^{\prime} \boldsymbol{\beta}\right) e^{v}}=\frac{D\left(\boldsymbol{s}^{\prime} \boldsymbol{\beta}\right) e^{-u} e^{v}}{D\left(\boldsymbol{s}^{\prime} \boldsymbol{\beta}\right) e^{v}}=e^{-u}
$$


This economic outcome-oriented measure of eco-efficiency by definition lies between zero and one. ${ }^{4}$ It measures the economic output of the $\mathrm{k}$-th firm relative to the maximum attainable economic outcome by a fully-efficient firm for a given level of environmental damage. Note that this specification of eco-efficiency is different from the traditional one given at the beginning of this section, which is defined as the ratio between economic output and aggregate environmental pressure.

\subsection{Eco-Performance: Dynamics and Decomposition}

As earlier mentioned, in order to obtain a more comprehensive understanding of farms' ecological performance, we introduce the concept of eco-performance change which builds upon the literature on total factor productivity (TFP) (mainly Balk 2001; Orea 2002; Coelli et al. 2005; Kumbhakar and Lovell 2000). Analogous to Orea (2002), our eco-performance analysis is largely based on the Malmquist TFP index and its three differentials: scale change, technical change and efficiency change. Our approach deviates from Orea (2002) in the sense that we do not consider total factor productivity but rather total eco-pressure productivity (or in short: eco-performance).

Caves, Christensen, and Diewert (1982) measure TFP change based on Malmquist input or output distance functions, respectively. Basically, the Malmquist TFP change index is defined by the ratio of the distances of each data point relative to a common technology. Here, the common technology is respresented by the pressure conversion frontier (4). Furthermore, we make use of an output-oriented index, i.e. the vector of ecological pressures $\left(s_{t}\right)$ is assumed to be fixed while economic outcome $(y)$ is maximized given the pressuregeneration technology. Eco-performance change between two periods $\mathrm{f}$ and $\mathrm{t}$ can then be expressed as the geometric mean of the Malmquist indices for periods $f$ and $t$. Furthermore, we assume that some degree of eco-inefficiency can be observed for most production units, i.e. $d_{0}^{s}\left(y_{f}, s_{f}\right) \leq 1$ and $d_{0}^{t}\left(y_{t}, s_{t}\right) \leq 1$. Hence, the conversion of environmental pressures to economic output are additionally subject to efficiency changes (Coelli et al. 2005). We can express eco-performance change as:

$$
m_{0}\left(y_{s}, s_{f}, y_{t}, s_{t}\right)=\frac{d_{0}^{t}\left(y_{t}, s_{t}\right)}{d_{0}^{s}\left(y_{s}, s_{f}\right)} \times\left[\frac{d_{0}^{s}\left(y_{t}, s_{t}\right)}{d_{0}^{s}\left(y_{r}, s_{f}\right)} \times \frac{d_{0}^{t}\left(y_{t}, s_{t}\right)}{d_{0}^{t}\left(y_{f}, s_{f}\right)}\right]^{1 / 2}
$$

where $d_{0}^{s}\left(y_{t}, s_{t}\right)$ stands for the distance from the period t observation to the technology in $r$ and the second term of the Eq. 6 reflects changes in the underlying pressure generating technology over time, while the term outside the square brackets reflects eco-efficiency change. The presented Malmquist index does not make any assumptions with respect to returns to scale. However, as mentioned by multiple authors, Eq. 6 is only true if the technology exhibits constant returns to scale. Among others, Balk (2001) and Orea (2002) state that productivity can also be improved through improvements in the scale of operations, a component that the Malmquist index defined by Caves, Christensen, and Diewert (1982) does not capture. As noted earlier, we explicitly allow for variable returns to scale. It is therefore pivotal to add a scale component to the eco-performance index. Consequently, we

\footnotetext{
${ }^{4}$ We choose an outcome-oriented over a emission-oriented measure because we argue that in most cases it is more realistic to assume that farms seek to maximize economic output for a given level of environmental damage than to minimize emissions for a given level of output.
} 
make use of the widely accepted and utilized generalized Malmquist TFP index suggested by Orea (2002), which takes account of scale economies and complies with the requirements of identity, separability and monotonicity: ${ }^{5}$

$$
\begin{aligned}
\ln g_{0}= & \ln m_{o}+\frac{1}{2} \sum_{n=1}^{N}\left[\left(-\sum_{n=1}^{N} \frac{\partial \ln D_{0}(t)}{\partial \ln s_{n}}-1\right) \times e_{n}(t)\right. \\
& \left.+\left(-\sum_{n=1}^{N} \frac{\partial \ln D_{0}(r)}{\partial \ln s_{n}}-1\right) \times e_{n}(f)\right] \times \ln \left(\frac{s_{n}^{t}}{s_{n}^{f}}\right)
\end{aligned}
$$

with

$$
\text { Returns to pressure scale }{ }^{t}=e_{n}(t)=\frac{\partial \ln D_{0}(t) / \partial \ln s_{n}}{\sum_{n=1}^{N} \partial \ln D_{0}(t) / \partial \ln s_{n}}
$$

Further information regarding the operationalization of the productivity change decomposition by Orea (2002) is given in Sect. 4.

\subsection{GHG Emissions and Eco-Performance}

In the context of this study, we wish to focus specifically on GHG emissions. For that purpose, we define ecological damage in terms of GHG emissions as a function of the three major pressures on the climate, namely carbon dioxide $\left(\mathrm{S}_{\mathrm{CO}_{2}}\right)$, methane $\left(\mathrm{S}_{\mathrm{CH}_{4}}\right)$ and nitrous dioxide $\left(s_{\mathrm{N}_{2} \mathrm{O}}\right.$ ). Contrary to that, Kuosmanen and Kortelainen (2005) argue in favor of using only one aggregate measure for greenhouse gases as they contribute the same environmental problem, namely the greenhouse effect. We, however, believe it is important to decompose climatic stress into the above-mentioned pressures for two reasons. First, despite the fact that GHGs contribute to the same effect, they do have diverging relative impacts on the climate and thus on the ecological damage they cause, which should be accounted for. Second, as stated earlier, physical input and output quantities are implicitly included in $D$. In the farming context, they are linked to emissions through different activities and management practices. For instance, $\mathrm{N}_{2} \mathrm{O}$ emissions are associated with the application of nitrogen fertilizers, while methane primarily stems from the digestive system of ruminants. If we seek to evaluate these pressures in terms of the climate stress they produce, we implicitly evaluate different farming activities, a fact we would miss if we used an aggregated measure of GHGs.

Analogous to the pressure conversion frontier, by inserting GHG emissions into Eq. 4 and using firm revenue $(r)$ as economic outcome variable, we obtain the 'GHG conversion frontier':

\footnotetext{
${ }^{5}$ In general, there is no consensus in the literature on what productivity change measure to use best. While some TFP indices such as the Fisher or Tornquist index require price information, others such as the Malmquist or Hicks-Morsteen index do not depend on prices. O'Donnell (2012) argues in favor of the Hicks-Morsteen-Index. Balk (2001) and Orea (2002) advocate the use of the Malmquist index, which has experienced quite extensive use in empirical work (e.g Coelli and Rao 2005; Song, Han, and Deng 2016; Frick and Sauer 2018). What is more, Briec and Kerstens (2011) show in their study that there are only minor numerical discrepancies between the Malmquist and Hicks-Morsteen-Index.
} 


$$
r=D\left(s_{\mathrm{CO}_{2}}, s_{\mathrm{CH}_{4}}, s_{\mathrm{N}_{2} \mathrm{O}}, t ; \boldsymbol{\beta}\right) e^{-u+v}
$$

Based on (8), all metrics and concepts presented in Sects. 2.1 and 2.2 are equally true for GHG emissions. This allows us to assess firms' returns to emission scale, emission efficiency (EE) as well as eco-performance with respect to GHG emissions. Variable $t$ reflects the time to properly capture the time-dependency structure of marginal emission damage (Field and Field 2009).

It is largely undisputed that anthropogenic global warming through the emission of greenhouse gases has detrimental environmental impacts. However, according to Weitzman (2012) it is barely possible (if not impossible) to properly quantify high-temperature damage. GHG emissions are not environmentally harmful per se if they do not exceed the carrying capacity of the atmosphere. However, starting from that threshold, additional GHG emissions can lead to erratic climate conditions and, by extension, to ecological harm. The exact relationship between greenhouse gas releases and high-temperature damage $D\left(s_{\mathrm{CO}_{2}}, \mathrm{~S}_{\mathrm{CH}_{4}}, \mathrm{~s}_{\mathrm{N}_{2} \mathrm{O}}\right)$ is fairly unknown and is seen as highly complex and nonlinear (Kuosmanen and Kortelainen 2005). This is why we cannot attribute the adverse effects of climate change to a specific farm in practice. As such, and in line with Kuosmanen and Kortelainen (2005), we do not seek to compute the ultimate environmental impacts of farms' ambient GHG releases through climate change, and instead stick to the level of environmental pressures or climate stress factors, respectively.

\section{Data}

As will be seen in the following, data requirements for estimating the above-mentioned conceptual model largely deviate from most other studies in the field of production economics. First, the model has no direct recourse to physical inputs and outputs. Second, besides farm accountancy data, we need several additional datasets for our analysis. There is no database of farm-level greenhouse gas emissions in Europe, nor can GHG emissions easily be retrieved from farm accountancy data only, although such data serve as an important source for calculating farm-level GHG emissions.

\subsection{Farm Accountancy Dataset}

The most important dataset of our empirical analysis is farm accountancy data for Germany, and more specifically for the federal state of Bavaria. This dataset is part of the European Farm Accountancy Data Network (FADN). Data are annually collected from approximately 3100 farms. It is an unbalanced farm-level panel dataset and participation is voluntary. The sample is stratified with respect to farm location, size classes, and specialization of the farms. In addition to financial records, socio-economic information is provided such as the education level of the farm manager, number of household members or the on-farm labor structure. The sample covers the time period from 2005 through 2014.

Although our empirical example is based on a regional sample of farms, we believe that our empirical findings are relevant in a larger European context. The case of Bavaria may be regarded as somewhat representative for other European regions as well. For instance, farms in Bavaria managed on average 34.7 ha of land in 2014 which is similar to average farm sizes in, e.g., Ireland, Belgium and the Netherlands (European Commission 2019b). Also, Bavarian dairy farmers kept on average 34.1 livestock units (LUs) of dairy cows 
Table 1 Subsample description-farm types (2005-2014)

\begin{tabular}{lllll}
\hline & Dairy & Swine & Mixed & Crop \\
\hline Number of observations & 9574 & 3796 & 2558 & 5318 \\
Number of farms & 1513 & 585 & 711 & 919 \\
Avg. participation (years) & 6.33 & 6.49 & 3.6 & 5.79 \\
Revenue (Const. 2014 Euro) & & & & 109,261 \\
$\quad$ - Mean & 154,453 & 296,348 & 172,499 & 115,343 \\
- SD & 88,074 & 205,914 & 143,274 & 241 \\
- Min & 11,087 & 700 & 403 & $1,442,213$ \\
$\quad$ - Max & $1,139,323$ & $1,534,219$ & $1,464,453$ & \\
\hline
\end{tabular}

between 2005 and 2014. This value lies only slightly above the average for all European regions (30.4). On average, Bavarian pig farms managed 154.4 LUs of pigs, which was approximately equal to the European average of 154.8 LUs. As for the labor structure, on average 1.6 average work units (AWUs) worked on Bavarian farms between 2005 and 2014, while the European average was 1.5 AWUs in the same period (European Commission 2019b).

For this research, we focus on four important farm types in European agriculture, namely dairy farms, pig fattening farms, mixed farms (livestock and crop) and crop farms. Farms are categorized according to their principal activity within the farm business. Specialized farms (dairy, pig and crop) are assigned to the respective farm type if the output share of their characteristic produces exceed 66\% in total revenues (milk, fattening pigs, grains). As for mixed farms (i.e. crop-livestock systems), no primary product accounts for more than $66 \%$ of total revenues. Only farms are included that provide information for at least 3 years. Organic farms were excluded from the sample based on the assumption of a fundamental different technology compared to conventional farms. In our application, farm revenue enters the model as the economic outcome variable, which is defined as the value of sales (taxes included, subsidies excluded). In order to eliminate price effects from our analysis we deflate revenues from different farming activities to the base year 2014. Price indices of agricultural producer prices provided by the German Statistical Office are used for deflating the data. Table 1 gives an overview of the subsamples used for the empirical analysis and the respective deflated revenues.

\subsection{Construction of Farm-Level GHG Emissions and Additional Data}

As agricultural GHG emissions are considered a nonpoint source pollution, direct measurement is rather impractical and costly when applied to a large number of farms (Paustian et al. 2004; Smith et al. 2008; Dick et al. 2008). Therefore researchers have frequently made use of indirect methods to estimate agricultural GHG emissions, where emissions are regarded as the outcome of a combination of farm activities and management practices (Baldoni, Coderoni, and Esposti 2018). In a multitude of studies, greenhouse gas emissions are approximated by making use of the ISO-standardized life cycle analysis (LCA) inventory approach, where emissions associated with each stage of the production change are cumulated (ISO 2006). These studies, however, only consider small samples of specific farm types and rarely consider their evolution over time. This is largely due to the expensive data-collection procedure. 
An alternative procedure for recovering farm-level GHG emissions is based on the guidelines of the United Nations Framework Convention on Climate Change (UNFCCC) and the Intergovernmental Panel on Climate Change (IPCC), which are designed for national GHG inventories, and are thus considered an internationally accepted and widely applicable standard (e.g. Olesen et al. 2006; Casey and Holden 2005). Furthermore, we use the methodological extensions to the IPCC method added by Haenel et al. (2018). A multitude of studies have shown that the approach is also well-suited for retrieving GHG emissions at the microlevel (Coderoni and Esposti 2018; Baldoni, Coderoni, and Esposti 2017, 2018; Dick et al. 2008). While earlier studies were still relatively limited with respect to time and sample scope, recent advances towards integrating farm accountancy data allow larger samples and comparisons across farms and time.

The basic idea is that GHG emissions at farm level can be retrieved from the following relationship:

$$
E m_{i t}=\sum_{l=1}^{L}\left(A D_{i t l} \times E F_{t l}\right)
$$

where $E m_{i t}$ describes total GHG emissions of farm k at time t. $A D_{i t l}$ refers to some activity data of farm $\mathrm{k}$ at time $\mathrm{t}$, referring to emission source $l=1, \ldots, L . A D_{i t l}$ describes the activity data (e.g. number of animals, fertilizer quantities or diesel consumption) of the 1-th activity at time t, while $E F_{t l}$ stands for (implied) emission factors which characterize the emission quantities associated with a specific activity (e.g. $\mathrm{kg} \mathrm{CH}_{4}$ released per dairy cow per year, or $\mathrm{kg} \mathrm{N}_{2} \mathrm{O}$ associated with application of $1 \mathrm{~kg}$ of mineral fertilizer).

We define relevant system boundaries at the farm-gate to keep the inventory transparent and comprehensible. Also, procedures within the farm-gate leading to emissions are directly within the control of the farms and can therefore unambiguously be attributed to farmers' performance (Coderoni and Esposti 2018). In terms of which emission sources should be included in the inventory, first and foremost, we make use of the Common Reporting Format Sector 3 "Agriculture" of the United Nations Framework Convention on Climate Change (UNFCCC 2014). On top of that, carbon dioxide emissions from the use of energy, more specifically from on-farm fuel combustion is included, which refers to the UNFCCC "Energy" sector. An overview of the major emission sources, activity data and emission factors is given in Table 2. We distinguish between the three major categories: livestock, crop cultivation and energy use.

As for livestock, animal numbers are retrieved from the farm accountancy dataset. For a more precise calculation, animal categories such as cattle, pig and poultry were further decomposed according to Haenel et al. (2018). ${ }^{6}$

While GHG emissions from livestock keeping can fairly easily be recovered from farm accountancy information, this is not true for crop cultivation, as additional information is needed for retrieving activity data. The major challenge lies in the fact that the prime purpose of farm accountancy data is to record production, and rarely the evaluation of ecological performance. Figure A1 illustrates how additional data sources can be utilized beside the farm accountancy data to calculate GHG emissions.

\footnotetext{
${ }^{6}$ The following distinction has been made with respect to nitrogen excretion rates as well as enteric fermentation rates: (a) Horses: heavy horses, ponies and light horses (b) Cattle: calves, male beef cattle, heifers, mature males $>2$ years, dairy cows and suckler cows (c) Pigs: weaners, fattening pigs, boars, sows (d) Sheep (e) Poultry: laying hens, pullets, broilers, other poultry.
} 


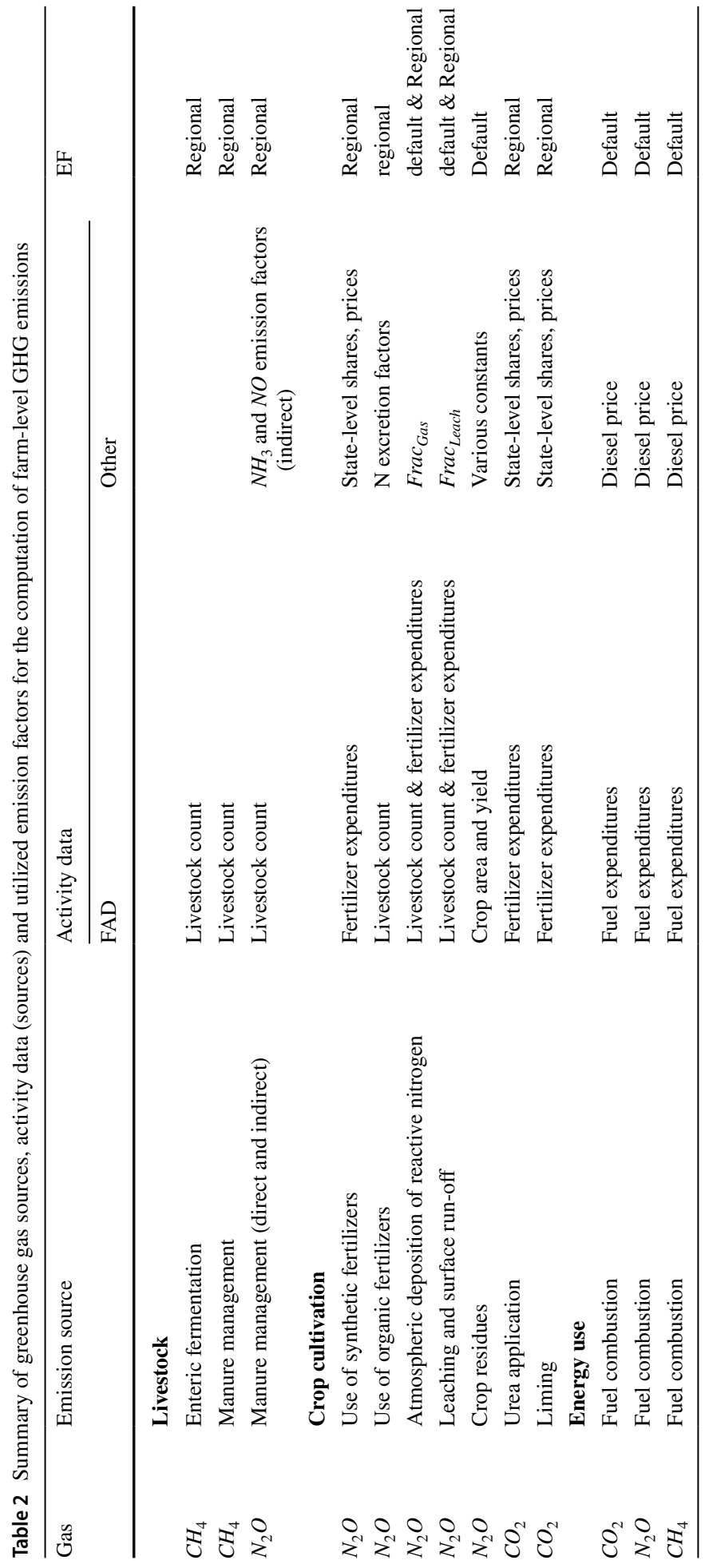


Table 3 Farm-level GHG emissions and emission intensities of Bavarian farms

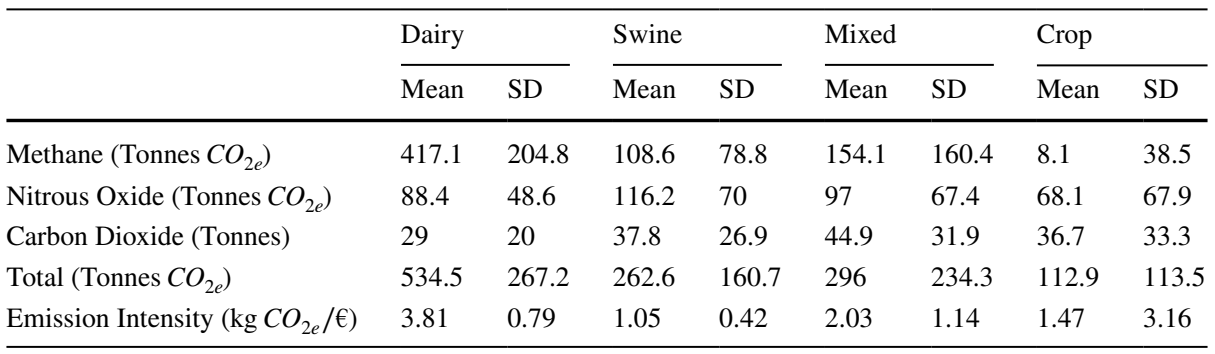

As already found by Coderoni and Esposti (2018), a major challenge is to recover physical fertilizer quantities when the dataset only provides information on fertilizer expenditures. Coderoni and Esposti (2018) use a fixed conversion factor for fertilizer expenditures to retrieve quantities. We argue against this approach, since quantities of, say, nitrogen vary in terms of their price and their relative share within all fertilizers used over time. Therefore, as a means to recover the individual quantities of synthetic $\mathrm{N}$ application, we construct a double-weighted mean in a 4-step procedure. ${ }^{7}$ A description of the method can be found in the appendix as well as more details on the emission sources. The interested reader is referred to Haenel et al. (2018), who describe and discuss the IPCC method in detail for the German context. There, all underlying computation formulas for retrieving the respective activity data can be found.

\subsection{Post-Processing, GHG Emissions and Emission Intensities}

Although the IPCC method for reconstructing GHG emissions as described in Sect. 3.2 is widely accepted in the literature, the fact that farm-level GHG emissions are computed by utilizing data from different aggregation levels inevitably leads to some anomalies in the data. For this reason, we apply the BACON (blocked adaptive computationally efficient outlier nominators) algorithm as suggested by Billor, Hadi, and Velleman (2000) to detect multivariate outliers. In total, 580 observations are excluded ( 162 dairy, 109 pigs, 83 mixed, 179 crop) from the analysis, i.e. 2.51 per cent of all observations across the four farm types. ${ }^{8}$

Summary statistics of the GHG releases per farm can be found in Table 3. To ensure comparability, methane and nitrous oxide emissions were converted to $\mathrm{CO}_{2}$-equivalents. To that end, $\mathrm{N}_{2} \mathrm{O}$ and $\mathrm{CH}_{4}$ quantities were multiplied by their respective global warming potentials (298 and 34, respectively) as per the IPCC's Fifth Assessment Report (IPCC 2013). ${ }^{9}$ There are clear differences across the inspected farm types. On average, dairy farms have the highest GHG emission rate per year $\left(417.1 \mathrm{t} \mathrm{CO}_{2 e}\right)$ followed by mixed and pig farms. Crop farms show the smallest number of total $\mathrm{GHG}$ emissions per farm. As for dairy farms, unsurprisingly, methane is the major contributor to total emissions. This is

\footnotetext{
7 This also applies to urea and $\mathrm{CaCO}$. We obtained diesel quantities in a similar fashion, which allows us to recover $\mathrm{CO}_{2}$ emissions from fuel combustion.

${ }^{8}$ For crop farms, we did not consider methane in the outlier detection procedure, since $75 \%$ of that subsample did not produce any methane at all in the period 2005-2014.

9 Considering the inclusion of climate carbon feedback and a 100-year time horizon.
} 
also true for mixed farms. For the other types, it is nitrous oxide. $\mathrm{CO}_{2}$ is present in all farming systems but plays a lesser role with respect to total emissions apart from crop farming. It is worthwhile to note the large standard deviations concerning all farm types and greenhouse gases. This alludes to a high level of heterogeneity across individual farms. These first descriptive results are comparable to other findings, e.g. by Baldoni, Coderoni, and Esposti (2017) and Coderoni and Esposti (2018) for Italian farms.

To get a first impression of farms' capacity to convert GHG emissions to monetary output, we compute emission intensities (EI, compare Baldoni, Coderoni, and Esposti 2018). EI measures emissions in $\mathrm{kg} \mathrm{CO}_{2 e}$ per unit of output expressed in constant Euros. Table 3 shows that dairy farms have the highest EI of $3.81 \mathrm{~kg} \mathrm{CO}_{2 e} / €$, i.e. on average a Bavarian dairy farm emits $3.81 \mathrm{~kg} \mathrm{CO}_{2 e}$ to produce one Euro of output. Mixed farms are next $(2.03$ $\left.\mathrm{CO}_{2 e} / €\right)$, followed by crop farms $\left(1.47 \mathrm{CO}_{2 e} / €\right)$ and finally pig fattening farms $\left(1.05 \mathrm{CO}_{2 e} /\right.$ $€)$.

\section{Empirical Specification}

\subsection{Estimation Strategy}

In our study we employ the stochastic frontier (SF) approach as first proposed by Aigner, Lovell, and Schmidt (1977) and Meeusen and van den Broeck (1977). The production economics literature delivers a wide range of candidate stochastic frontier models for the estimation of the GHG conversion frontier (8) in a panel data setting; for a recent overview see e.g. Kellermann (2015) and Kumbhakar, Lien, and Hardaker (2014). Examples for regularly used SF models are the 'error components model' by Battese and Coelli (1992), the 'efficiency effects' approach by Battese and Coelli (1995) and the 'true fixed/random effects' model by Greene (2005). We decide to use the stochastic frontier specification introduced by Kumbhakar, Lien, and Hardaker $(2014, \mathrm{KLH})$ and write (8) as: ${ }^{10}$

$$
r_{k n t}=\alpha_{0}+D\left(s_{k n t}, \boldsymbol{\beta}\right)+\mu_{k}+v_{k t}+\eta_{k}-u_{k t}
$$

Here, the error consists of four components. $\eta_{k}>0$ and $u_{k t}>0$ account for inefficiency, whilst $\mu_{k}$ and $v_{k t}$ represent firm effects and noise, respectively. As Kumbhakar, Lien, and Hardaker (2014) note, all of these components have already been implemented in one way or another, yet not all at the same time. Contrary to most commonly utilized SF models (e.g. Greene 2005; Wang and Ho 2010; Chen, Schmidt, and Wang 2014), the KLH model properly distinguishes between time-varying $\left(u_{k t}\right)$ and time-invariant inefficiency $\left(\eta_{k}\right)$, while also accounting for the effect of unobserved farm heterogeneity on outcome. ${ }^{11}$

\footnotetext{
${ }^{10}$ Kumbhakar, Lien, and Hardaker (2014) mention various shortcomings of earlier SF models. For instance, Battese and Coelli (1992) only allow inefficiency to change over time exponentially. Also, firm effects (fixed or random) are often not clearly distinguished from (persistent) inefficiency. The KLH model overcomes many of the problems associated with previous SF models as shown below.

11 Time-varying (transient) inefficiency is related to time-varying issues such as the adaptation to changes in the firms' environment and is therefore a short-term concept which changes over time. It is related to operative business activities. Persistent inefficiency is a long run concept and stable over time. It is related to the structure of a company. If a company is persistent (structurally) inefficient this may require the introduction of several policy measures such as change in ownership, increasing/reducing the size of a company etc.
} 
Kumbhakar, Lien, and Hardaker (2014) suggest a multi-step estimation procedure for the KLH model. To apply this, (10) must be operationalized by rewriting it as follows:

$$
r_{k t}=\alpha_{0}^{*}+D\left(s_{k t}, \boldsymbol{\beta}\right)+\alpha_{k}+\epsilon_{k t}
$$

where $\alpha_{0}^{*}=\alpha_{0}-E\left(\eta_{k}\right)-E\left(u_{k t}\right) ; \alpha_{k}=\mu-\eta_{k}+E\left(\eta_{k}\right)$ and $\epsilon_{k t}=v_{k t}-u_{i t}+E\left(u_{k t}\right)$. Here, $\alpha_{k}$ and $\epsilon_{k t}$ have zero mean and constant variance. Technical details regarding the estimation of Eq. 11 can be found in the appendix and in Kumbhakar, Wang, and Horncastle (2015).

As we wish to focus on GHG emissions in this study, methane $\left(s_{\mathrm{CH}_{4}, k t}\right)$, nitrous oxide $\left(s_{\mathrm{N}_{2} \mathrm{O}, k t}\right)$ and carbon dioxide $\left(s_{\mathrm{CO}_{2} 0, k t}\right)$ enter in the operationalized GHG conversion function (11) as independent variables. Revenue $r_{k t}$ is the dependent variable. In terms of the functional form of the 'pressure/ghg conversion function' (8), Orea and Wall (2017) suggest a weighted mean of the environmental pressures (s) to depict ecological damage caused by these pressures. We argue against this approach in that it appears too simplistic to properly describe the unknown true relationship between environmental pressures (here: emissions) and ecological damage. As stated earlier, the relationship between emissions and damage is assumed to be highly complex and nonlinear (Kuosmanen and Kortelainen 2005). To adequately account for this nonlinearity and complexity and to constrain our functional form as little as possible, we suggest the use of the second-order flexible translog functional form for $D(s)$. We add a time variable to properly account for the panel structure of the data and to accommodate the time-specific character of the climate damage function as proposed by Field and Field (2009). Hence, we specify the empirical stochastic GHG conversion frontier (10) as:

$$
\begin{aligned}
\ln r_{k t}= & \alpha_{0}+\sum_{n=1}^{N} \alpha_{n} \ln s_{n k t}+\frac{1}{2} \sum_{n=1}^{N} \sum_{l=1}^{N} \alpha_{n l} \ln s_{n k t} \ln s_{l k t} \\
& +\beta_{t} t+\frac{1}{2} \beta_{t t} t^{2}+\sum_{n=1}^{N} \beta_{n t} t \ln s_{n k t}+\mu_{k}+v_{k t}+\eta_{k}-u_{k t}
\end{aligned}
$$

where $\alpha_{0}, \alpha_{n}, \alpha_{n l}, \beta_{t}, \beta_{t t}$ and $\beta_{n t}$ are unknown parameters to be estimated. $t$ represents time. ${ }^{12}$ The multi-step procedure for estimating Eq. 12 is conducted separately for each farm typology, since it is assumed that they relate to distinct reference technologies. Partial outcome elasticities of the greenhouse gases can be retrieved in the standard fashion:

$$
e_{n k t}=\frac{\ln r_{k t}}{\ln s_{n k t}}=\alpha_{n}+\sum_{l=1} \alpha_{n l} \ln s_{l k t}
$$

Returns to emission scale (RTES) are the sum of the partial elasticities:

$$
\operatorname{RTES}_{k t}=\sum_{n=1} e_{n k t} \ln s_{n k t}
$$

In order to evaluate the validity of our models, we test several alternative specifications against our baseline model (12). First, we test the hypothesis that there is in fact an ecological-technical change with respect to emissions over time. Second, we test if technical

\footnotetext{
12 We provide an alternative specification including capital and labor as a robustness check (see Appendix A.6).
} 
change might be better described as Hicks-neutral. Third, we test the translog formulation against the Cobb-Douglas functional form.

\subsection{Computation of Productivity Dynamics}

As described in Sect. 2.2 and in line with Orea (2002), the eco-performance change (EPC) is composed of three components, emission efficiency change (EEC), ecological-technical change with respect to emissions (ETC) and emission scale change (ESC). The EEC index can be computed as follows (Coelli et al. 2005):

$$
E E C_{k(f t)}=\frac{E E_{k t}}{E E_{k f}}
$$

ETC between two adjacent periods can be calculated as the geometric mean of the partial derivatives of (12) with respect to time:

$$
E T C_{i(f t)}=\exp \left(\frac{1}{2}\left[\frac{\partial \ln r_{i f}}{\partial f}+\frac{\partial \ln r_{i t}}{\partial t}\right]\right)
$$

Finally, in accordance with Orea (2002), emission scale change is computed as:

$$
E S C_{i(f t)}=\exp \left(\frac{1}{2} \sum_{n=1}^{N}\left[e_{n i f} \mathrm{SF}_{i f}+e_{n i t} \mathrm{SF}_{i t}\right] \ln \left(\frac{s_{n i t}}{s_{n i f}}\right)\right)
$$

where $S F_{i f}=\left(e_{i f}-1\right) / e_{i f} ; e_{i f}=\sum_{n=1}^{N} e_{n i f}$ and $e_{n i f}=\partial \ln r_{i s} / \partial \ln s_{i f}$. Total emission-performance change (or emission productivity change) is the sum of the single components:

$$
\mathrm{EPC}_{i(f t)}=\mathrm{EEC}_{i(f t)}+\mathrm{ETC}_{i(f t)}+\mathrm{ESC}_{i(f t)}
$$

\section{Empirical Results and Discussion}

\subsection{Model Specification}

Parameter estimates of the empirical greenhouse gas conversion function (12) were obtained by estimating a fixed effects regression model for each farm type separately. Hausman tests were conducted, which rejected both the random effects model and the pooled regression model at the $1 \%$ significance level for all farm types. Cobb-Douglas specifications are rejected in favor of the translog model. Furthermore, Wald tests rejected the hypotheses of zero technical change as well as Hicks-neutral technical change. Therefore we opted for specifications that allow for non-monotonic and non-neutral technical change. Estimation results of the favored models are presented in table 4.

All first-order coefficients can be interpreted as partial elasticities of GHGs at the sample mean, which are positive and significantly different from zero for all farm types and greenhouse gases. For instance, a $1 \%$ decrease in methane is, ceteris paribus, associated with a $0.68 \%$ decrease in revenues for an average dairy farm. Evaluating at the sample mean, we can find that the same GHGs have a different association with revenues depending on the farm type. Reducing methane is most costly for dairy farms, in that their 
Table 4 KLM step 1 result table—fixed effect regression for 4 different farm types in Bavarian agriculture

\begin{tabular}{|c|c|c|c|c|}
\hline & \multicolumn{4}{|c|}{ Dependent variable: } \\
\hline & \multicolumn{4}{|l|}{$\ln (\operatorname{Rev})$} \\
\hline & Dairy & Pig & Mixed & Crop \\
\hline $\ln \left(\mathrm{CH}_{4}\right)$ & $\begin{array}{l}0.677 * * * \\
(0.023)\end{array}$ & $\begin{array}{l}0.310 * * * \\
(0.020)\end{array}$ & $\begin{array}{l}0.042 * * \\
(0.020)\end{array}$ & $\begin{array}{l}0.035 * * * \\
(0.010)\end{array}$ \\
\hline $\ln \left(N_{2} O\right)$ & $\begin{array}{l}0.077 * * * \\
(0.021)\end{array}$ & $\begin{array}{l}0.074 * * \\
(0.031)\end{array}$ & $\begin{array}{l}0.220 * * * \\
(0.035)\end{array}$ & $\begin{array}{l}0.133 * * * \\
(0.041)\end{array}$ \\
\hline $\ln \left(\mathrm{CO}_{2}\right)$ & $\begin{array}{l}0.227 * * * \\
(0.008)\end{array}$ & $\begin{array}{l}0.151 * * * \\
(0.015)\end{array}$ & $\begin{array}{l}0.264 * * * \\
(0.023)\end{array}$ & $\begin{array}{l}0.314 * * * \\
(0.038)\end{array}$ \\
\hline $.5 \times \ln \left(\mathrm{CH}_{4}\right)^{2}$ & $\begin{array}{l}0.551 * * * \\
(0.141)\end{array}$ & $\begin{array}{l}0.056^{* * * *} \\
(0.017)\end{array}$ & $\begin{array}{l}-0.035^{* *} \\
(0.015)\end{array}$ & $\begin{array}{l}0.005 \\
(0.004)\end{array}$ \\
\hline $.5 \times \ln \left(\mathrm{N}_{2} \mathrm{O}\right)^{2}$ & $\begin{array}{l}0.720 * * * \\
(0.152)\end{array}$ & $\begin{array}{l}-0.016 \\
(0.093)\end{array}$ & $\begin{array}{l}0.0004 \\
(0.082)\end{array}$ & $\begin{array}{l}0.105^{* * * *} \\
(0.024)\end{array}$ \\
\hline $.5 \times \ln \left(\mathrm{CO}_{2}\right)^{2}$ & $\begin{array}{l}0.185 * * * \\
(0.021)\end{array}$ & $\begin{array}{l}0.079 * * * \\
(0.026)\end{array}$ & $\begin{array}{l}0.093^{*} \\
(0.055)\end{array}$ & $\begin{array}{l}0.334 * * * \\
(0.040)\end{array}$ \\
\hline $\ln \left(\mathrm{CH}_{4}\right) \times \ln \left(\mathrm{N}_{2} \mathrm{O}\right)$ & $\begin{array}{l}-0.584 * * * \\
(0.134)\end{array}$ & $\begin{array}{l}0.013 \\
(0.042)\end{array}$ & $\begin{array}{l}0.020 \\
(0.024)\end{array}$ & $\begin{array}{l}-0.010 \\
(0.007)\end{array}$ \\
\hline $\ln \left(\mathrm{CH}_{4}\right) \times \ln \left(\mathrm{CO}_{2}\right)$ & $\begin{array}{l}0.032 \\
(0.043)\end{array}$ & $\begin{array}{l}-0.035 \\
(0.029)\end{array}$ & $\begin{array}{l}0.016 \\
(0.018)\end{array}$ & $\begin{array}{l}-0.004 \\
(0.008)\end{array}$ \\
\hline $\ln \left(\mathrm{N}_{2} \mathrm{O}\right) \times \log \left(\mathrm{CO}_{2}\right)$ & $\begin{array}{l}-0.132 * * * \\
(0.049)\end{array}$ & $\begin{array}{l}0.043 \\
(0.049)\end{array}$ & $\begin{array}{l}-0.022 \\
(0.062)\end{array}$ & $\begin{array}{l}-0.189 \text { *** } \\
(0.028)\end{array}$ \\
\hline Time & $\begin{array}{l}0.005^{* * *} \\
(0.001)\end{array}$ & $\begin{array}{l}0.022 * * * \\
(0.001)\end{array}$ & $\begin{array}{l}0.0003 \\
(0.002)\end{array}$ & $\begin{array}{l}0.005 \\
(0.004)\end{array}$ \\
\hline $.5 \times$ Time $^{2}$ & $\begin{array}{l}0.001 * * \\
(0.0004)\end{array}$ & $\begin{array}{l}0.006^{* * * *} \\
(0.001)\end{array}$ & $\begin{array}{l}0.004 * * * \\
(0.001)\end{array}$ & $\begin{array}{l}0.009 * * * \\
(0.001)\end{array}$ \\
\hline $\ln \left(\mathrm{CH}_{4}\right) \times$ Time & $\begin{array}{l}-0.018 \text { *** } \\
(0.004)\end{array}$ & $\begin{array}{l}0.004 \\
(0.003)\end{array}$ & $\begin{array}{l}0.0001 \\
(0.002)\end{array}$ & $\begin{array}{l}0.0002 \\
(0.001)\end{array}$ \\
\hline $\ln \left(\mathrm{N}_{2} \mathrm{O}\right) \times$ Time & $\begin{array}{l}0.017 * * * \\
(0.004)\end{array}$ & $\begin{array}{l}-0.001 \\
(0.005)\end{array}$ & $\begin{array}{l}-0.011^{*} \\
(0.006)\end{array}$ & $\begin{array}{l}0.005 \\
(0.004)\end{array}$ \\
\hline $\ln \left(\mathrm{CO}_{2}\right) \times$ Time & $\begin{array}{l}-0.002 \\
(0.002)\end{array}$ & $\begin{array}{l}0.003 \\
(0.003)\end{array}$ & $\begin{array}{l}0.015 * * * \\
(0.005)\end{array}$ & $\begin{array}{l}0.002 \\
(0.005)\end{array}$ \\
\hline Observations & 9,412 & 3,687 & 2,475 & 5,139 \\
\hline $\mathrm{R}^{2}$ & 0.509 & 0.371 & 0.236 & 0.161 \\
\hline F Statistic & $586.046^{* * * *}$ & $130.616^{* * * *}$ & $39.039 * * *$ & $57.642 * * *$ \\
\hline
\end{tabular}

$* \mathrm{p}<0.1 ; * * \mathrm{p}<0.05 ; * * * \mathrm{p}<0.01$

revenues decreased most significantly, compared with $\mathrm{N}_{2} \mathrm{O}$ and $\mathrm{CO}_{2}$. The same applies to pig fattening farms; however less pronounced. For mixed and crop farms, it is most expensive to reduce carbon dioxide followed by nitrous oxide, while methane only plays a minor role.

Steps two and three were estimated based on the results provided by Table 4 . Maximum likelihood (ML) estimations were conducted according to (19) and (20). In order to avoid biased standard errors, we computed bootstrapped standard errors. This allows us to 
Table 5 KLM step 2 result table-estimation of time-varying emission inefficiency (bootstrapped standard errors, $\mathrm{R}=1000$ )

\begin{tabular}{|c|c|c|c|c|c|c|c|c|}
\hline \multirow[t]{2}{*}{$Y=\hat{\epsilon}_{k t}$} & \multicolumn{2}{|l|}{ Dairy } & \multicolumn{2}{|l|}{ Pig } & \multicolumn{2}{|l|}{ Mixed } & \multicolumn{2}{|l|}{ Crop } \\
\hline & Estimate & SE & Estimate & SE & Estimate & SE & Estimate & SE \\
\hline Const. & 0.073 & $(0.004)$ & 0.104 & $(0.0059)$ & 0.083 & $(0.0096)$ & 0.211 & $(0.015)$ \\
\hline$\sigma^{2}$ & 0.017 & $(<0.001)$ & 0.03 & $(0.0015)$ & 0.025 & $(0.0014)$ & 0.119 & $(0.0083)$ \\
\hline$\gamma$ & 0.502 & $(0.0383)$ & 0.575 & $(0.0406)$ & 0.438 & $(0.0706)$ & 0.611 & $(0.0574)$ \\
\hline
\end{tabular}

Table 6 KLM step 3 result table-estimation of time-invariant emission inefficiency (bootstrapped standard errors, $\mathrm{R}=1000$ )

\begin{tabular}{|c|c|c|c|c|c|c|c|c|}
\hline \multirow[t]{2}{*}{$Y=\hat{\alpha}_{i}$} & \multicolumn{2}{|l|}{ Dairy } & \multicolumn{2}{|l|}{ Pig } & \multicolumn{2}{|l|}{ Mixed } & \multicolumn{2}{|l|}{ Crop } \\
\hline & Estimate & SE & Estimate & SE & Estimate & SE & Estimate & SE \\
\hline Const. & 5.275 & $(2.533)$ & 17.025 & (1.5973) & 11.564 & $(2.6558)$ & 8.878 & $(4.222)$ \\
\hline$\sigma^{2}$ & 0.056 & $(0.0022)$ & 0.59 & $(0.04)$ & 0.46 & $(0.062)$ & 0.796 & $(0.0953)$ \\
\hline$\gamma$ & 0.842 & $(0.0088)$ & 0.907 & $(0.0098)$ & 0.687 & $(0.0577)$ & 0.715 & $(0.0458)$ \\
\hline
\end{tabular}

Table 7 Percentage (\%) of monotonicity violations by greenhouse gas and farm type

\begin{tabular}{lllll}
\hline & Dairy & Pig & Mixed & Crop \\
\hline $\mathrm{CH}_{4}$ & 0 & 0.16 & 0.32 & 4.11 \\
$\mathrm{~N}_{2} \mathrm{O}$ & 26.54 & 2.74 & 0 & 0.86 \\
$\mathrm{CO}_{2}$ & 0.84 & 2.55 & 0.53 & 3.37 \\
Total & 27.25 & 3.58 & 0.85 & 8.25 \\
\hline
\end{tabular}

evaluate the statistical significance of the estimated parameters. ML results can be found in Tables 5 and 6. As can be seen, all relevant coefficients have small standard errors and are statistically significant, indicating that both permanent and time-varying efficiencies are present in all farm typologies. Additionally, likelihood ratio tests were conducted to test the SF models against Ordinary Least Squares (OLS), where OLS were rejected in favor of the frontier models for all farm types.

As shown by Sauer, Frohberg, and Hockmann (2006) and Henningsen and Henning (2009), the monotonicity condition plays an important conceptual role in stochastic frontier analyses. In order to sensibly interpret (partial) elasticities, efficiency scores and other derived metrics, we need to check if revenue is monotonically increasing in GHG emissions. It can be seen from Table 4 that all GHGs are monotonically increasing in revenues at the sample mean. Table 7 summarizes the results of the monotonicity checks at all data points. Mixed farms show very few monotonicity violations: $0.85 \%$ out of all observations. Furthermore, the monotonicity condition is violated for $8.25 \%$ of observed crop farms and for $3.58 \%$ of pig farms. As for dairy farms, monotonicity violations are found for $27.25 \%$ of all observations and is observed in particular for $\mathrm{N}_{2} \mathrm{O}$, where revenue decreases in $26.54 \%$ 

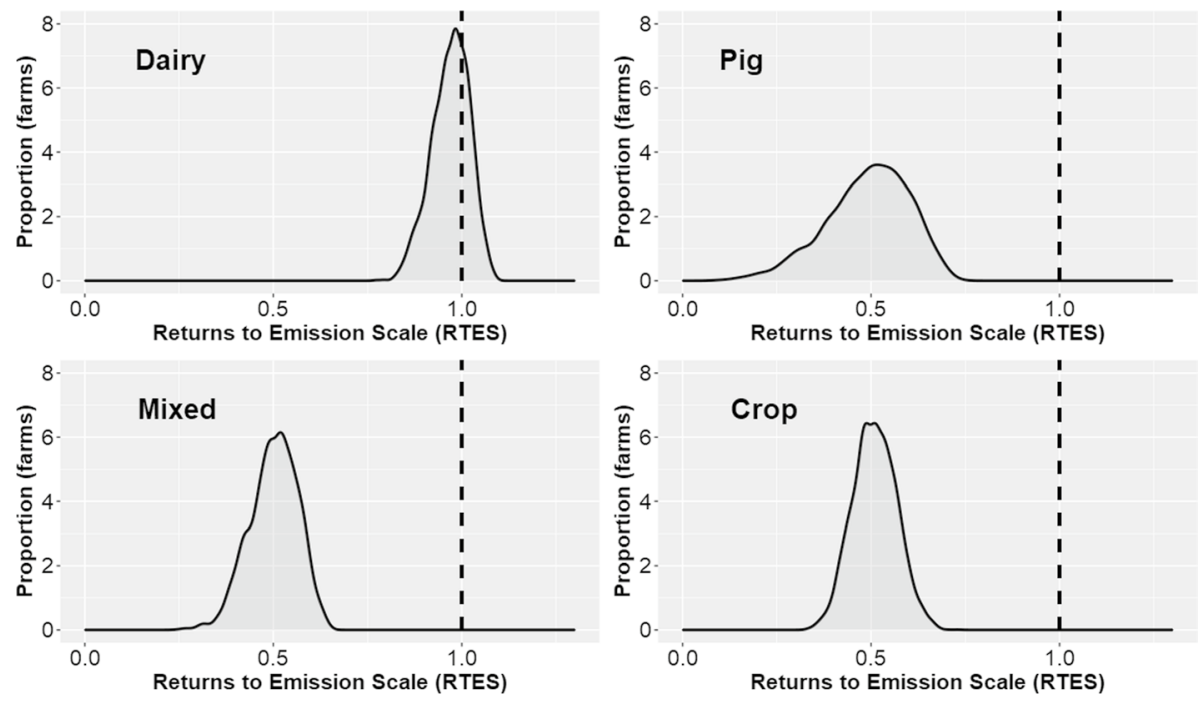

Fig. 1 Returns to emission scale (RTES) distributions of different farm types

of the observations. ${ }^{13}$ In accordance with Sauer, Frohberg, and Hockmann (2006), for further analysis, we have dropped all observations that violate the monotonicity condition and keep only those observations that are theoretically consistent. ${ }^{14}$

\subsection{Returns to Emission Scale}

This section presents the results for the returns to emission scale. Kernel density plots of farm type specific RTES values are provided in Fig. 1. This metric can be interpreted as the percentage change in revenues that is associated with a one percent increase (decrease) in total greenhouse gases. We find that almost all farms in the sample reveal decreasing returns to scale. However, $30 \%$ of dairies show increasing returns to scale. Mean RTES are 0.97, 0.49, 0.50, 0.51 for dairy, pig, mixed and crop farms, respectively. Hence, if a crop farm decreases its emissions by $1 \%$, revenues will decrease by $0.51 \%$, which is, as before, an underproportional decline in revenues.

Taking on a social planner perspective and giving economic performance (in the form of revenues) and GHG emissions equal weights, constant RTES would be desirable. In that case emissions and revenues would be proportionate and a one percent increase (decrease) in emissions would be associated with a one percent increase (decrease) in revenues. From

\footnotetext{
13 As stated above, we have evaluated several alternative model specifications. Beside having been rejected by standard statistical tests, they performed worse than our chosen specification with respect to theoretical consistency.

14 We avoid imposing monotonicity globally in order to retain functional flexibility in line with Sauer, Frohberg, and Hockmann (2006, p.161), who state "[...]if theoretical consistency holds for a range of observations, this 'consistency area' of the estimated frontier should be determined and clearly stated to the reader. Estimated relative efficiency scores hence only hold for observations which are part of this range."
} 

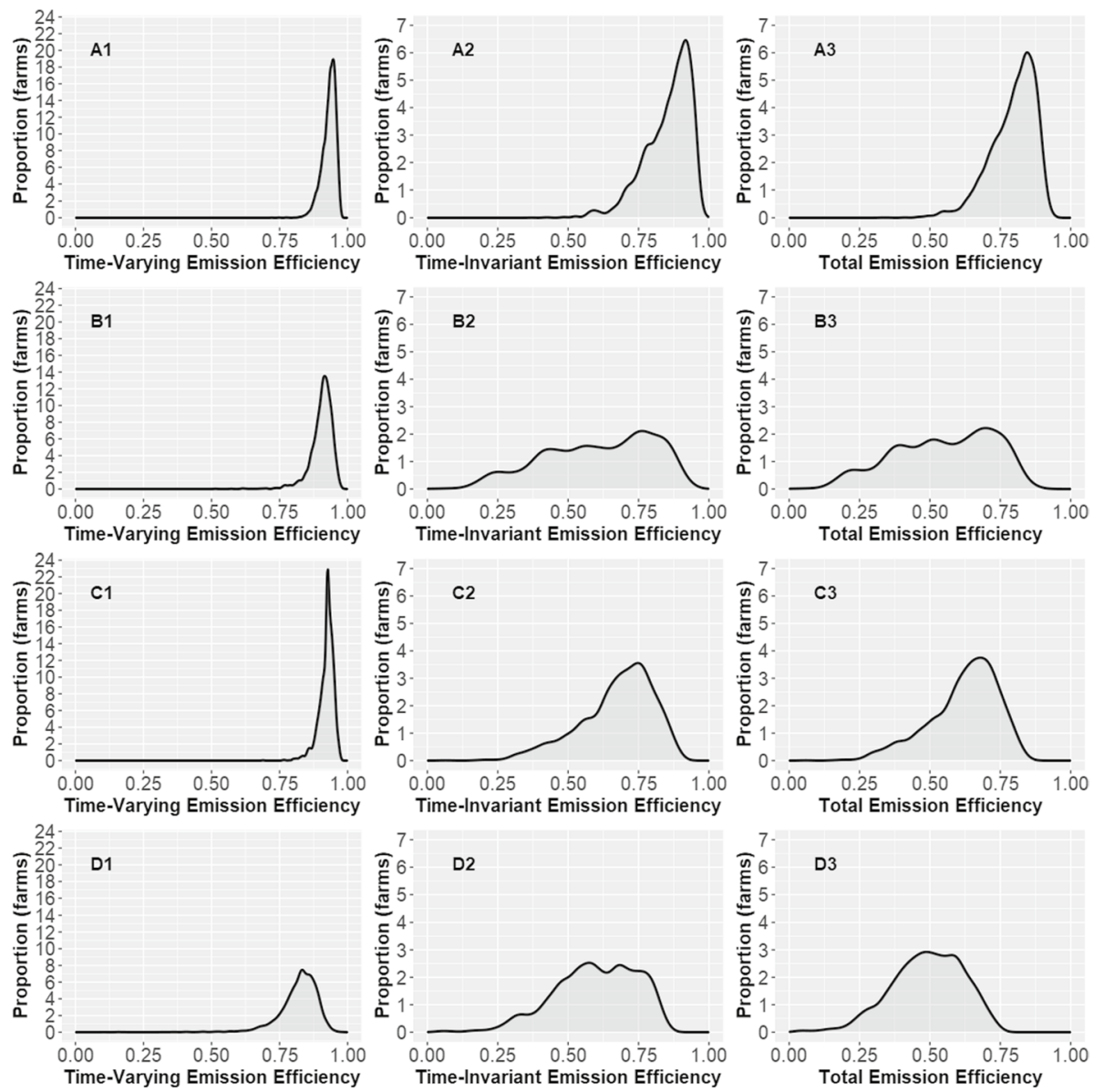

Fig. 2 Density plots of farms' residual (1), permanent (2) and total emission efficiency (3) Dairy (A), Pig (B), Mixed (C), Crop (D)

that perspective, dairy farms are on average close to the optimal emission scale, while the other farm types are far away from this point.

In allowing returns to emission/pressure scale to be variable, we can actually check whether or not the prevalent assumption of constant returns to scale as implied by most previous studies is plausible. Our results indicate that this is not the case for most Bavarian farms. Given similar production conditions, we can assume this holds also for other European regions. Whitney-Mann tests for all farming systems reject the null hypothesis that RTES are on average equal to one at standard confidence levels. However, evaluated at the sample mean, the $95 \%$ as well as the $99 \%$ confidence interval for the RTES of dairy farms contain the one (table Annex A2). Also, $90.6 \%$ of the observations in the dairy subsample exhibit RTES of between 0.9 and 1.1. Hence, assuming constant returns to scale appears rather plausible for dairy farms. All other farm types exhibit strongly decreasing returns to emission scale - also when evaluated at the sample mean.

According to our models, nearly all farms reveal quite extreme RTES and are a long way away from the optimal emission scale size from an ecological-economic perspective. 
A reason for this finding could be the fact that farms do not seek to optimize their scale size with respect to emissions but rather with respect to input use in order to optimize their economic performance, rather than their ecological performance. Hence, farms may be at their most productive (economically motivated) scale size which is desirable from a manager's perspective. If their input usage is linked to high levels of emissions, they might reveal decreasing returns to emission scale and are far away from the societally desirable, most productive emission scale size, which would imply fewer GHG emissions.

\subsection{Emission Efficiency}

Following Kumbhakar, Lien, and Hardaker (2014), time-varying emission efficiency scores were computed based on (19) while permanent efficiencies were calculated based on Eq. 20. The product for these two metrics equals total emission efficiency. Figure 2 presents the kernel density distributions of the individual efficiency scores for all farm types. Time-varying efficiency is very high across all farm types. Average scores range from 0.82 for crop farms to 0.92 for mixed farms and 0.93 for dairy farms (pig farms 0.9). Besides the higher mean scores, the spread for livestock-keeping farm typologies is smaller than the spread of crop farms.

Residual inefficiency stems from short-term rigidities on the farms (Kumbhakar, Lien, and Hardaker 2014). As livestock farmers are usually subject to a rather fixed environment in the form of stables, there is little room for improving emission efficiency in the short-run through improved management. The emission efficiency of crop farms, on the other hand, can be influenced by a multitude of short-term managerial decisions. For instance, the timing of certain activities plays an important role in terms of what yield can be obtained from a fixed set of inputs (International Fertilizer Industry Association (IFA) 1992). Thus, if inputs such as nitrogen fertilizers are applied in a timely fashion, inevitable nitrous oxide emissions from this input use can be better translated into output, and from that, eventually into revenue.

As for time-invariant efficiency, individual scores are on average lower than for residual efficiency. This is particularly true for pig, crop and mixed farms. The distributions are rather wide for pig, mixed and crop farms, i.e. there is greater heterogeneity across farms than for dairy farms. The fact that persistent efficiency is rather low could be indicative that farmers need to make structural changes to improve overall efficiency through e.g. farm size adjustments or investments in input-efficient, climate-friendly technologies. The high structural inefficiency may as well explain why on average the farmers operate under decreasing economies of scale.

Finally, overall efficiency is on average highest for dairy farms $(79.5 \%)$, followed by mixed farms (62.0\%), pig farms $(54.9 \%)$ and crop farms $(49.1 \%) .{ }^{15}$ This means that, say, pig farms only generate $54.9 \%$ of their maximum revenue given their level of damage on the climate. This also means by implication that farmers could considerably reduce climatic stress while maintaining the same level of revenue. This finding is in line with most previous studies on eco-efficiency (e.g. Picazo-Tadeo, Gómez-Limón, and Reig-Martínez 2011; Picazo-Tadeo, Beltrán-Esteve, and Gómez-Limón 2012; Godoy-Durán et al. 2017). As for crop farms, Bonfiglio, Arzeni, and Bodini (2017) and Gadanakis et al. (2015) find

\footnotetext{
${ }^{15}$ Efficiency levels are computed for the respective farm typology-specific technologies. Hence, we investigate efficiency levels relative to the farm type specific benchmarks and not for an overall meta-technology.
} 
mean eco-efficiency scores of $54.8 \%$ and $56.2 \%$ in Italy and the UK, respectively. Pérez Urdiales, Lansink, and Wall (2016) and Orea and Wall (2017) report average eco-efficiency levels for dairy farms in Asturia (Spain), which are markedly lower than the average in our sample. With regard to pig and mixed farms, we could not find any comparable study.

The huge potential for reducing climatic damage without affecting economic performance is particularly striking. From a societal point of view it is important to ponder potential reasons for the high level of eco-inefficiency found in our analysis. One reason could lie in the technical inefficiency of farms (Picazo-Tadeo, Gómez-Limón, and ReigMartínez 2011). Previous studies found a strong relationship between technical efficiency (TE) and eco-efficiency (EE) (Picazo-Tadeo, Gómez-Limón, and Reig-Martínez 2011; Beltrán-Esteve et al. 2014; Gadanakis et al. 2015). If farmers manage their inputs efficiently such that they can reduce their level of input use while maintaining their output level, then they are also likely to be eco-efficient. Conversely, the overuse of inputs such as nitrogen leads to technical and ecological inefficiency. Picazo-Tadeo and Reig-Martínez (2006) show in their study how pressures on the environment could be reduced by simply promoting best farming practices. This principle applies to both time-varying and persistent inefficiency. Differences in technical efficiencies may also serve as an explanation for emission efficiency differences in our case study. Mennig and Sauer (2019) find higher average TE scores for dairy farms than for crop farms in Bavaria between 2007 and 2011, which corresponds to our findings on eco-efficiency.

Furthermore, various other aspects have been found in the literature to have an effect on EE. Pérez Urdiales, Lansink, and Wall (2016) find that age has a negative effect on EE, i.e. older farmers are less eco-efficient, which is also shown by Reinhard, Lovell, and Thijssen (2002). Another reason for varying EE scores could relate to farmers' education level, which is assumed to be closely linked to managerial skills. According to Picazo-Tadeo, Gómez-Limón, and Reig-Martínez (2011) and Gadanakis et al. (2015) a higher education level is positively associated with eco-efficiency. Also, the prospect of farm succession seems to play an important role with respect to the level of EE. Pérez Urdiales, Lansink, and Wall (2016) and Bonfiglio, Arzeni, and Bodini (2017) show that if there is a positive expectation of the farm continuing, farms are more eco-efficient. Furthermore, policy interventions such as agri-environmental schemes (AES) or stricter environmental regulations have been found to be positively associated with the eco-efficiency of arable farms (Gadanakis et al. 2015; Pérez Urdiales, Lansink, and Wall 2016; Bonfiglio, Arzeni, and Bodini 2017).

\subsection{Eco-Performance Dynamics}

So far, we have only considered farms' eco-performance from a static point of view. In this section, we seek to investigate the dynamic structure of eco-performance and its components. As outlined in Sect. 4.2, eco-performance dynamics are determined by emission scale change, technical change and emission efficiency change. ${ }^{16}$ Ultimately, eco-performance can be viewed as the synthesis of the concepts presented in the previous sections.

Mean change rates of eco-performance and its components for all four subsamples from 2005 to 2014 are presented in Table 8. Annual change rates are $0.49 \%$ for dairy farms,

\footnotetext{
${ }^{16}$ Note, that the EEC only represents the transient component of inefficiency as persistent inefficiency is stable over time.
} 


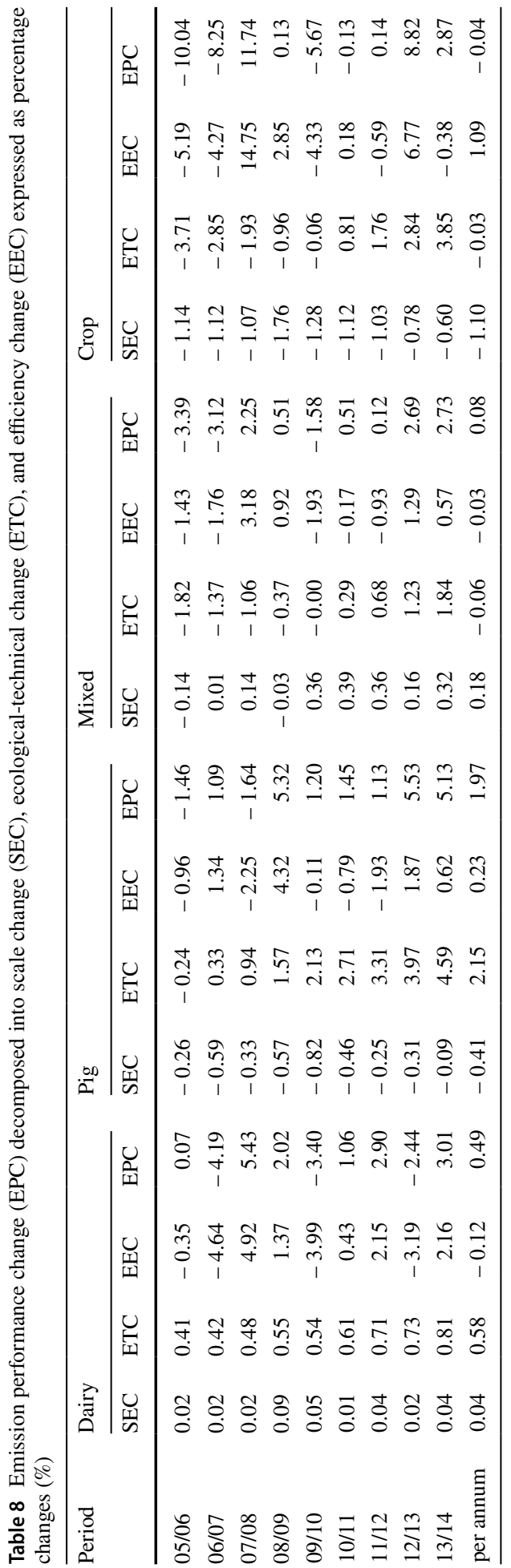



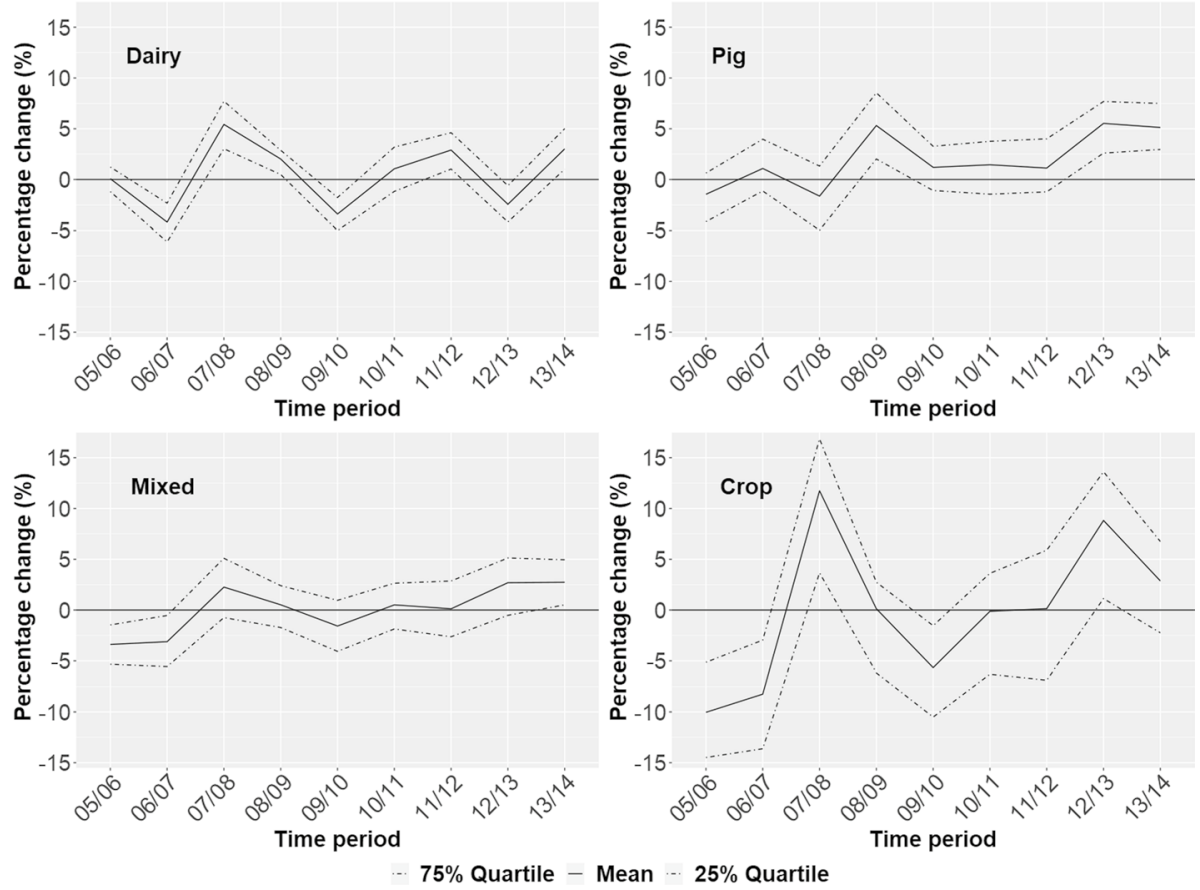

Fig. 3 The mean, first and third quartile values (middle, bottom and top lines) of emission productivity of Bavarian sample farms

$1.97 \%$ for pig farms, $0.08 \%$ for mixed farms and $-0.04 \%$ for crop farms. Eco-performance growth was mainly due to high average rates of technical progress with respect to emissions, except for crop farms. The fact that technical change is the main driver of eco-productivity has previously been shown in the literature (Kortelainen 2008; Picazo-Tadeo, Castillo-Giménez, and Beltrán-Esteve 2014; Beltrán-Esteve and Picazo-Tadeo 2017). Emission-efficiency is shown to be the highest (1.09\%) for crop farms. The other farm types reveal efficiency change rates rather close to zero. Average emission scale change rates are close to zero for all industries other than crop farms, where a negative annual development of, on average, $-1.1 \%$ has been identified.

As for scale-efficiency change, change rates were mostly negative for pig and crop farms and positive for dairy and mixed farms. Regarding technical change with respect to emissions, all industries reveal a positive trend in change rates. Yet, pig farms, mixed farms, and crop farms experienced technical progress in the period under review only as of $06 / 07$, $09 / 10$ and $10 / 11$, respectively. One reason for the technical regression in the pressure-generating technology could be that the underlying production technology may have altered such that the input combination of farmers leaned toward more emission-intensive inputs. As concerns the emission efficiency change, sharp increases in efficiency are found for the period 2007/2008 for dairy, mixed and crop farms and for 2008/2009 with respect to pig farms. This is followed by periods of decreasing growth, efficiency decay and recovery at different rates and following different patterns later on.

Figure 3 depicts the mean, first and third quantile values of the composite eco-performance patterns between 2005 and 2014. As before, we can see different patterns for 


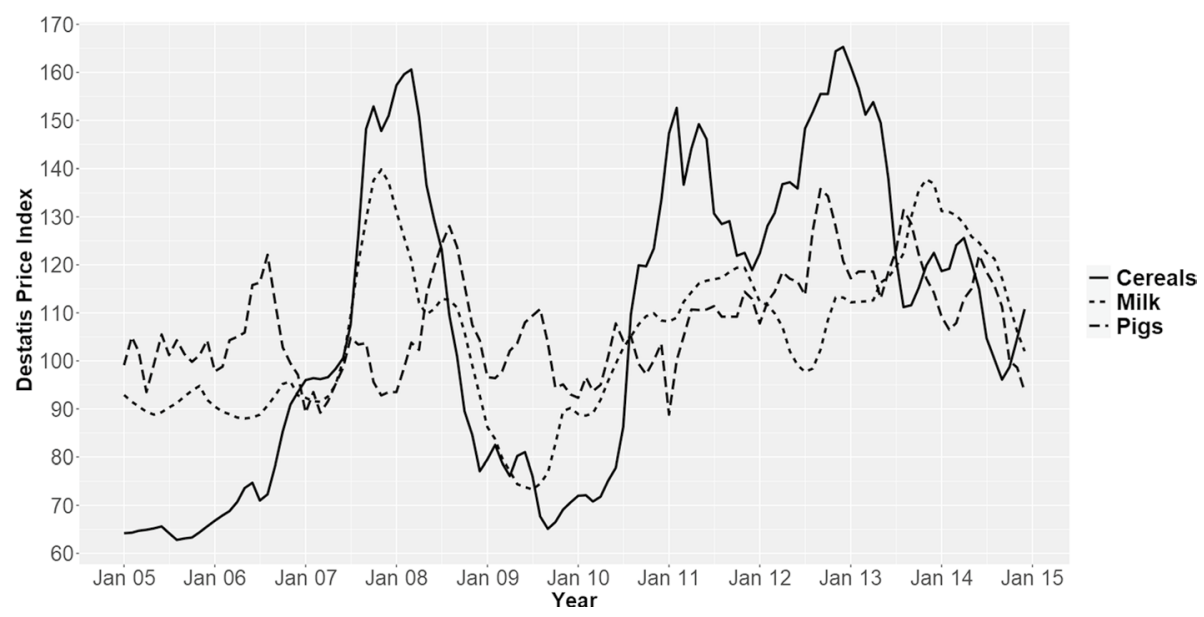

Fig. 4 Destatis price index from January 2005 to December 2014 (monthly): cereals, milk, pigs

different industries. The smallest average degree of volatility was found in mixed farms, while crop farms were characterized by high fluctuations. Dairy and pig farms were found to be somewhat between the two extremes. Hence, the above-mentioned overall eco-performance improvement did not develop in a monotonically increasing fashion for any of the analyzed farm types. Additionally, the distribution of change rates expressed as the interquartile range is highest for crop farms, indicating considerable intra-industry eco-performance differences. That indicator is at its lowest for dairy farms, i.e. less intra-industry differences can be observed with respect to emission performance.

As outlined in Table 8 technical change with respect to emissions is the key factor behind the overall eco-performance growth for most industries (except arable farms), while eco-efficiency change is the key factor behind the eco-performance growth patterns. As mentioned previously, one major factor that influences time-varying efficiency is the managerial ability of farmers regarding their input use. This gives rise to the essential question as to which contexts are farmers producing more efficiently in, compared to others. Figure 4 possibly delivers an explanation for that phenomenon. Taking the case of crop farms, we observe the real price development of cereal prices in the relevant time period (solid line in Fig. 4). Low-price periods are followed by a decline in the eco-performance of crop farms (compare Fig. 3), while high-price periods are usually followed by increasing rates in eco-productivity. Hence, if high output prices are expected, farmers could seek to manage their constrained inputs more efficiently than in times of low-price expectations. Similar but less pronounced movements can also be found for milk prices and eco-productivity of dairy farms as well as for pig prices, and for the eco-performance movements of pig fattening farms. Finally, assuming a close relationship between eco-performance and total factor productivity (TFP), Frick and Sauer (2018) and Mennig and Sauer (2019) find similar TFP patterns for dairy and crop farms in Bavaria.

\subsection{Policy Implications}

The fact that most farms in the sample show strongly decreasing returns to emission scale raises the question as to what legislators can do if their objective is to observe a 
proportional relationship between emissions and revenue, i.e. if emissions are changed by one per cent, revenues change accordingly by one per cent. One obvious answer would be to regulate farm size to balance GHG emissions and economic outcome (input scale effect). However, this approach could have several consequences, e.g. total factor productivity could decrease as farms' technical efficiency might decrease due to impaired input use management or underutilized resources. Hence, (regional) added value in agriculture could decline, which might have unintended consequences for parts of the rural population. Another approach is to foster policies that aim at decreasing the amount of emissions per unit of input (input management effect). This would allow farmers to remain at a productive scale in terms of the input-output relationship and at the same time move towards the most eco-productive scale. For instance, legislators could promote the use of precision agriculture practices for crop producers such as global positioning systems, where input application and agronomic practices are matched with soil attributes (Gadanakis et al. 2015). As for livestock farms, manure management systems could be improved to reduce GHG emissions per livestock unit. For instance, Petersen et al. (2013) find that covering up manure storage facilities or treating manure with additives can substantially decrease methane releases. These measures are expected to also positively affect persistent emission efficency of farms through investments leading to (eco-)structural changes.

As for farmers' general eco-performance with respect to greenhouse gas emissions, there are ample options available to policy-makers. First, legislators could promote agricultural training programs aiming at improving farmers' managerial skills, which eventually translates into improved input-management and better emission efficiency. Picazo-Tadeo, Beltrán-Esteve, and Gómez-Limón (2012, p.806) note that policies aiming at increasing productive efficiency "[...] can be considered the most cost-efficient way of reducing environmental pressures without reducing farmers' income". Legislators should thereby take farm type specificities into account as performance varies strongly across farm types.

Second, various policy options exist that aim to internalize environmental externalities induced by farming activities. This also applies to the emission of greenhouse gases. By more effectively conditioning farmers' income to their climate-protection performance, a behavior which is more oriented towards the public good can be expected (compare Picazo-Tadeo, Beltrán-Esteve, and Gómez-Limón 2012; Beltrán-Esteve et al. 2014). E.g. Picazo-Tadeo, Gómez-Limón, and Reig-Martínez (2011) demand a stronger commitment of EU policy-makers to the principle of conditionality, i.e. only farmers that comply with ambitious ecological standards should benefit from public resources. Moreover, farmers could be sanctioned for adverse climatic performance (polluter-pays principle) or could be financially rewarded for climate-friendly farming practices (provider-gets principle). The most pressing need for action applies to those farm types that were found to be on average very emission-inefficient, such as crop and pig farms. Furthermore, EU second-pillar agrienvironmental schemes (AES) are considered to promote eco-efficiency. However, several authors note the cost-inefficiency of such AES programs (Picazo-Tadeo, Gómez-Limón, and Reig-Martínez 2011; Beltrán-Esteve et al. 2014; Bonfiglio, Arzeni, and Bodini 2017).

Finally, policy-makers are not overly concerned about short-run fluctuations in emission-performance. Since the ultimate objective is to mitigate climate change and its adverse effects on the environment, a positive long-run development of eco-performance and its determinants is pivotal to that end. Beside the aforementioned instruments to improve returns to emission scale and eco-efficiency, ecological-technical progress could be promoted. Beside the aforementioned adoption of existing climate-friendly technologies, legislators could stimulate eco-innovations in the context of climate-smart agriculture. Long, Blok, and Coninx (2016) recommend, among other things, financial support for start-up 
companies and tax-cuts for research and development activities. This could boost technological improvements and have a positive impact on farms' emission-performance and finally on their relative climate change mitigation potential.

\section{Summary and Concluding Remarks}

Increasing concerns over the environmental implications of farming activities as well as the need for increasing productivity require the development of monitoring and evaluating instruments with respect to the ecological-economic performance of farm businesses, in short "eco-performance". This is particularly true with respect to the trade-off between climatic impact and the economic performance of farms as the adverse effects of global warming become ever more apparent. Measuring eco-performance in terms of GHG emissions is important, as it might provide policy-makers and farm managers with sound information for designing measures to reduce GHG emissions while at the same time improving economic performance.

This paper has presented an approach to assess firms' relative climate change mitigation potential by building upon and further developing the concept of eco-efficiency (Kuosmanen and Kortelainen 2005; Orea and Wall 2017). We presented a parametric stochastic frontier approach capable of capturing eco-performance dynamics over time. Unlike previous studies on eco-efficiency, we allowed for a complex functional form to aggregate ecological (climatic) pressures into environmental damage. The resulting 'pressure conversion function' describes how well ecological pressures translate into economic output. Moreover, we considered the fact that the underlying pressure-generating technology might exhibit variable returns to pressure scale. Finally, our theoretical framework let us analyze eco-performance dynamics and its components - technical change, scale change and ecoefficiency change by means of a generalized Malmquist productivity index.

Our empirical application focused on four different farm types in the German federal state of Bavaria, which is a significant and somewhat representative region in the European Union for the years 2005 to 2014. In order to approximate GHG emissions at farmlevel, we make use of recent methodological developments in the literature by applying and downscaling the IPCC guidelines for national greenhouse gas inventories to the firmlevel. Besides farm accountancy data, a unique combination of various data sources is used to estimate the pressure-generating technology separately for dairy, pig, mixed and crop farms, based on a stochastic frontier model for panel data based distinguishing between time-varying and persistent eco-inefficiency.

The main findings of the study were the following. Our study revealed that, evaluated at the sample mean, all greenhouse gases (namely methane, nitrous oxide and carbon dioxide) were positively associated with farms' revenues. Mann-Whitney tests reject the hypothesis of constant returns to scale for all farm types. Nearly all farms in our sample experience strongly decreasing returns to their scale of GHG emissions. However, $90 \%$ of dairy farms exhibit emission scale elasticities of between 0.9 and 1.1, i.e. they are close to the optimal emission scale of one. As for emission efficiencies, farms revealed little time-varying ecoinefficiency and rather high levels of persistent inefficiency. Overall, the farms in our sample were very eco-inefficient. Dairy farms were on average least eco-inefficient ( 80\%) followed by mixed ( $\sim 60 \%)$ and pig farms $(\sim 55 \%)$ and crop farms ( $\sim 50 \%)$. Based on the two above-mentioned criteria, returns to emission scale and emission-efficiency, dairy farms performed best, followed by pig farms, mixed farms and finally crop farms. In terms of 
eco-performance dynamics, our results showed that pig farms revealed the highest annual growth rates. Dairy farms and crop farms showed less pronounced positive growth. Mixed farms exhibited very little eco-performance growth between 2005 and 2014.

As this study presents a novel approach for measuring eco-performance at the microlevel, it is subject to several limitations. First, our method for retrieving GHG emissions at the micro-level represents an approximation of the true GHG releases. By combining data from different aggregation levels and sources, some imprecisions are inevitable. Also, our method only accounts for GHG releases. We do not consider possible farm management options that serve as carbon sinks. Second, our eco-performance measure does not imply total ecological pressures. Instead, we focus on climatic stress. Therefore, we are not able to capture potentially important interactions between climatic stress and other ecological stresses such as nitrogen surpluses or pesticide risk. Third, some caution is due when interpreting our estimation results, especially with respect to dairy farms. As there is a non-negligible proportion of farms that do not comply with the monotonicity condition, we have only made statements on theoretically consistent observations. Finally, it should be noted that the presented concept does not refer to farms' absolute ecological performance, but relative eco-performance with respect to GHG emissions. Even if farms were completely eco-efficient, absolute emission levels could still be too high, in that the carrying capacity of the atmosphere is exceeded.

Several policy options for improving farms' emission-performance can be suggested: Promoting the development of eco-innovations and climate-smart technologies as well as fostering the adoption of already existing climate-smart technologies might be one way forward. Also, the EU's common agricultural policy could be more strongly oriented toward the principle of conditionality, i.e. only farmers that comply with high emission standards would profit from public support. Other options include training programs to improve farmers' managerial skills and raise environmental awareness. Nevertheless, even if farmers exploit their full potential regarding emission performance, more drastic policy measures to reduce absolute levels of GHG released might be necessary to further limit climate change.

Finally, we would like to highlight potential avenues for further research. From a methodological point of view, it would be interesting to directly incorporate eco-efficiency determinants into the error term of the pressure conversion frontier. This would allow for the evaluation of their impact on eco-efficiency. Moreover, it would be interesting make comparisons across pressure-generating technologies by using a metafrontier framework. Furthermore, the consideration of more environmental pressures than GHG emissions would be insightful from a more general sustainability perspective, as it would provide a more holistic picture of the ecology-economy trade-off. From an empirical standpoint, data on environmental pressures can be rare and difficult to obtain. It would be advisable to enrich, e.g., farm accountancy data with additional information on environmental pressures. This would also be helpful in further improving the accuracy of the farm-level greenhouse-gas-inventory methodology presented in this paper. Another interesting avenue for future research could be the evaluation of the econnection between the environmental Kuznet curve and eco-efficiency at the micro-level. Lastly, it would also be insightful to extend the eco-performance concept by incorporating factors representing the social dimension of a more holistic sustainability concept.

Supplementary Information The online version contains supplementary material available at https://doi. org/10.1007/s10640-021-00642-1. 
Acknowledgements The authors greatly appreciate comments received from all anonymous reviewers who helped to substantially improve earlier versions of the manuscript. Furthermore, the authors would like to thank Phoebe Koundouri for handling this manuscript and the participants of the second meeting of the OECD network on agricultural total factor productivity and the environment for their constructive feedback. This research was partially supported by the Bavarian State Ministry of Sciences, Research and the Arts in the context of the Bavarian Climate Research Network (bayklif).

Funding Open Access funding enabled and organized by Projekt DEAL.

Open Access This article is licensed under a Creative Commons Attribution 4.0 International License, which permits use, sharing, adaptation, distribution and reproduction in any medium or format, as long as you give appropriate credit to the original author(s) and the source, provide a link to the Creative Commons licence, and indicate if changes were made. The images or other third party material in this article are included in the article's Creative Commons licence, unless indicated otherwise in a credit line to the material. If material is not included in the article's Creative Commons licence and your intended use is not permitted by statutory regulation or exceeds the permitted use, you will need to obtain permission directly from the copyright holder. To view a copy of this licence, visit http://creativecommons.org/licenses/by/4.0/.

\section{References}

Aigner D, Lovell C, Schmidt P (1977) Formulation and estimation of stochastic frontier production function models. J Econom 6:21-37

Atkinson SE, Tsionas MG (2018) Shadow directional distance functions with bads: GMM estimation of optimal directions and efficiencies. Empir Econ 54:207-230

Baldoni E, Coderoni S, Esposti R (2018) The complex farm-level relationship between environmental performance and productivity: the case of carbon footprint of Lombardy farms. Environ Sci Policy 89:73-82

Baldoni E, Coderoni S, Esposti R (2017) The productivity and environment nexus with farm-level data. The case of carbon footprint in lombardy FADN farms. Bio-Based Appl Econo 6:119-137

Balk BM (2001) Scale efficiency and productivity change. J Product Anal 15:159-183

Ball VE, Lovell CAK, Luu H, Nehring R (2004) Environmental incorporating of impacts in the measurement growth productivity agricultural. J Agric Resource Econ 29:436-460

Battese GE, Coelli TJ (1995) A model for technical inefficiency effects in a stochastic frontier production function for panel data. Empir Econ 20:325-332

Battese GE, Coelli TJ (1992) Frontier production functions, technical efficiency and panel data: With application to paddy farmers in India. J Product Anal 3:153-169

Battese GE, Coelli TJ (1988) Prediction of firm-level technical efficiencies with a generalized frontier production function and panel data. J Econ 38:387-399

Beltrán-Esteve M, Gómez-Limón JA, Picazo-Tadeo AJ, Reig-Martínez E (2014) A metafrontier directional distance function approach to assessing eco-efficiency. J Product Anal 41:69-83

Beltrán-Esteve M, Picazo-Tadeo AJ (2017) Assessing environmental performance in the European Union: eco-innovation versus catching-up. Energy Policy 104:240-252

Billor N, Hadi AS, Velleman PF (2000) BACON: blocked adaptive computationally efficient outlier nominators. Comput Stat Data Anal 34:279-298

Bonfiglio A, Arzeni A, Bodini A (2017) Assessing eco-efficiency of arable farms in rural areas. Agric Syst $151: 114-125$

Briec W, Kerstens K (2011) The hicks-moorsteen productivity index satisfies the determinateness axiom. Manchester School 79:765-775

Camarero M, Castillo-Giménez J, Picazo-Tadeo AJ, Tamarit C (2014) Is eco-efficiency in greenhouse gas emissions converging among European Union countries? Empir Econ 47:143-168

Casey JW, Holden NM (2005) Analysis of greenhouse gas emissions from the average Irish milk production system. Agric Syst 86:97-114

Caves DW, Christensen LR, Diewert WE (1982) The economic theory of index numbers and the measurement of input, output, and productivity. Econometrica 50:1393-1414

Chambers RG, Lee H (1986) Constrained output maximization and US agriculture. Appl Econ 18:347-357

Chen YY, Schmidt P, Wang HJ (2014) Consistent estimation of the fixed effects stochastic frontier model. J Econ 181:65-76 
Coderoni S, Esposti R (2018) CAP payments and agricultural GHG emissions in Italy. A farm-level assessment. Sci Total Environ 627:427-433

Coderoni S, Esposti R (2014) Is there a long-term relationship between agricultural ghg emissions and productivity growth? A dynamic panel data approach. Environ Resource Econ 58:273-302

Coelli TJ, Prasada Rao DS, O’Donnell CJ, Battese GE (2005) An introduction to efficiency and productivity analysis, 2nd edn. Springer, New York

Coelli TJ, Rao DS (2005) Total factor productivity growth in agriculture: a Malmquist index analysis of 93 countries, 1980-2000. Agric Econ 32:115-134

Dick J, Smith P, mith R, Lilly A, Moxey A, Booth J, Campbell C, Coulter D (2008) Calculating farm scale greenhouse gas emissions., pp. 0-29

European Commission (2019a) CAP Specific Objectives ...explained-Brief No 4. Working paper No. 1, Brussels

European Commission (2019b) Eurostat database. http://ec.europa.eu/eurostat/data/database. Retrieved 28 Aug, 2019

European Environment Agency (2019) Annual European Union Greenhouse Gas Inventory 1990-2009 and inventory report 2019. Working paper No. 2

FAO (2017) The future of food and agriculture-trends and challenges. FAO, Rome

Field BC, Field MK (2009) Environmental economics : an introduction, 5th edn. McGraw-Hill Irwin, Boston

Førsund FR (2018) Multi-equation modelling of desirable and undesirable outputs satisfying the materials balance. Empir Econ 54:67-99

Frick F, Sauer J (2018) Deregulation and productivity: empirical evidence on dairy production. Am J Agric Econ 100:354-378

Gadanakis Y, Bennett R, Park J, Areal FJ (2015) Evaluating the sustainable intensification of arable farms. J Environ Manag 150:288-298

Godoy-Durán Á, Galdeano- Gómez E, Pérez-Mesa JC, Piedra-Muñoz L (2017) Assessing eco-efficiency and the determinants of horticultural family-farming in southeast Spain. J Environ Manag 204:594-604

Gómez-Calvet R, Conesa D, Gómez-Calvet AR, Tortosa-Ausina E (2016) On the dynamics of eco-efficiency performance in the European Union. Comput Oper Res 66:336-350

Greene W (2005) Reconsidering heterogeneity in panel data estimators of the stochastic frontier model. J Econ 126:269-303

Haenel HD, Rösemann C, Dämmgen U, Döring U, Wulf S, Eurich-Menden B, Freibauer A, Döhler H, Schreiner C, Osterburg B (2018) Calculations of gaseous and particulate emissions from German agriculture 1990-2016: report on methods and data (RMD) submission 2018. Braunschweig: Johann Heinrich von Thuenen-Institut, Thuenen Rep 57

Henningsen A, Henning CH (2009) Imposing regional monotonicity on translog stochastic production frontiers with a simple three-step procedure. J Product Anal 32:217-229

International Fertilizer Industry Association (IFA) (1992) World fertilizer use manual. IFA, International Fertilizer Industry Association, Paris

IPCC (2006) 2006 IPCC Guidelines for National Greenhouse Gas Inventories, Eggleston HS, Buendia L, Miwa K, Ngara T, Tanabe K (eds) Japan: National Greenhouse Gas Inventories Programme.

IPCC (2013) Climate change 2013: the physical science basis. In: Stocker VBTF, Qin D, Plattner G-K, Tignor M, Allen SK, Boschung J, Nauels A, Xia Y, Midgley P (eds) Contribution of working group I to the fifth assessment report of the intergovernmental panel on climate change. Cambridge University Press, Cambridge and New York

ISO (2006) ISO 14044. Environmental management—life cycle assessment—requirements and guidelines

Kellermann MA (2015) Total factor productivity decomposition and unobserved heterogeneity in stochastic frontier models. Agric Resource Econ Rev 44:124-148

Kortelainen M (2008) Dynamic environmental performance analysis: a Malmquist index approach. Ecol Econ 64:701-715

Kumbhakar SC, Bokusheva R (2009) Modelling farm production decisions under an expenditure constraint. Eur Rev Agric Econ 36:343-367

Kumbhakar SC, Lien G, Hardaker JB (2014) Technical efficiency in competing panel data models: a study of Norwegian grain farming. J Product Anal 41:321-337

Kumbhakar SC, Lovell CAK (2000) Stochastic Frontier analysis. Cambridge University Press, Cambridge, UK

Kumbhakar SC, Wang HJ, Horncastle AP (2015) A practitioner's guide to stochastic frontier analysis using Stata. Cambridge University Press, New York

Kuosmanen T, Kortelainen M (2005) Measuring eco-efficiency of production with data. J Ind Ecol 9:59-72 
Long TB, Blok V, Coninx I (2016) Barriers to the adoption and diffusion of technological innovations for climate-smart agriculture in Europe: evidence from the Netherlands, France, Switzerland and Italy. J Clean Prod 112:9-21

Malikov E, Bokusheva R, Kumbhakar SC (2018) A hedonic-output-index-based approach to modeling polluting technologies. Empir Econ 54:287-308

Managi S (2006) Are there increasing returns to pollution abatement? Empirical analytics of the environmental Kuznets curve in pesticides. Ecol Econ 58:617-636

Managi S, Opaluch JJ, Jin D, Grigalunas TA (2005) Environmental regulations and technological change in the offshore oil and gas industry. Land Econ 81:303-319

Meeusen W, van den Broeck J (1977) Technical efficiency and dimension of the firm: some results on the use of frontier production functions. Empir Econ 2:109-122

Mennig P, Sauer J (2019) The impact of agri-environment schemes on farm productivity: a DID-matching approach. European Review of Agricultural Economics, pp. 1-49

O'Donnell CJ (2012) An aggregate quantity framework for measuring and decomposing productivity change. J Product Anal 38:255-272

O'Donnell CJ, Rao DS, Battese GE (2008) Metafrontier frameworks for the study of firm-level efficiencies and technology ratios. Empir Econ 34:231-255

Olesen JE, Schelde K, Weiske A, Weisbjerg MR, Asman WA, Djurhuus J (2006) Modelling greenhouse gas emissions from European conventional and organic dairy farms. Agric Ecosyst Environ 112:207-220

Orea L (2002) Parametric decomposition of a generalized Malmquist productivity index. J Product Anal 18:5-22

Orea L, Wall A (2017) A parametric approach to estimating eco-efficiency. J Agric Econ 68:901-907

Paustian K, Babcock B, Hatfield J, Kling C, Lal R, McCarl B, McLaughlin S, Mosier A, Post W, Rice C, Robertson G, Rosenberg N, Rosenzweig C, Schlesinger W, Zilberman D (2004) Climate change and greenhouse gas mitigation: challenges and opportunities for agriculture, vol 141. Council for Agricultural Science and Technology, Ames

Pérez Urdiales M, Lansink AO, Wall A (2016) Eco-efficiency among dairy farmers: the importance of socio-economic characteristics and farmer attitudes. Environ Resource Econ 64:559-574

Petersen SO, Blanchard M, Chadwick D, Del Prado A, Edouard N, Mosquera J, Sommer SG (2013) Manure management for greenhouse gas mitigation. Animal 7:266-282

Picazo-Tadeo AJ, Beltrán-Esteve M, Gómez-Limón JA (2012) Assessing eco-efficiency with directional distance functions. Eur J Oper Res 220:798-809

Picazo-Tadeo AJ, Castillo-Giménez J, Beltrán-Esteve M (2014) An intertemporal approach to measuring environmental performance with directional distance functions: Greenhouse gas emissions in the European Union. Ecol Econ 100:173-182

Picazo-Tadeo AJ, Gómez-Limón JA, Reig-Martínez E (2011) Assessing farming eco-efficiency: a data envelopment analysis approach. J Environ Manag 92:1154-1164

Picazo-Tadeo AJ, Reig-Martínez E (2006) Agricultural externalities and environmental regulation: evaluating good practice in citrus production. Appl Econ 38:1327-1334

Reinhard S, Lovell CAK, Thijssen G (2002) Analysis of environmental efficiency variation. Am J Agric Econ 84:1054-1065

Sauer J, Frohberg K, Hockmann H (2006) Stochastic efficiency measurement: the curse of theoretical consistency. J Appl Econ 9:139-165

Smith P, Martino D, Cai Z, Gwary D, Janzen H, Kumar P, McCarl B, Ogle S, O’Mara F, Rice C, Scholes B, Sirotenko O, Howden M, McAllister T, Pan G, Romanenkov V, Schneider U, Towprayoon S, Wattenbach M, Smith J (2008) Greenhouse gas mitigation in agriculture. Philos Trans R Soc B 363:789-813

Song W, Han Z, Deng X (2016) Changes in productivity, efficiency and technology of China's crop production under rural restructuring. J Rural Stud 47:563-576

UNFCCC (2014) Guidelines for the preparation of national communications by Parties included in Annex I to the Convention. UNFCCC reporting guidelines on annual greenhouse gas inventories. Warsaw, Part I

Wang HJ, Ho CW (2010) Estimating fixed-effect panel stochastic frontier models by model transformation. J Econ 157:286-296

Weitzman ML (2012) GHG targets as insurance against catastrophic climate damages. J Public Econ Theory $14: 221-244$

Publisher's Note Springer Nature remains neutral with regard to jurisdictional claims in published maps and institutional affiliations. 